\title{
International Dollar Flows
}

Banegas, Ayelen, Ruth Judson, Charles Sims, and Viktors Stebunovs

\section{Please cite paper as:}

Banegas, Ayelen, Ruth Judson, Charles Sims, and Viktors

Stebunovs (2015). International Dollar Flows.

International Finance Discussion Papers 1144.

http://dx.doi.org/10.17016/IFDP.2015.1144

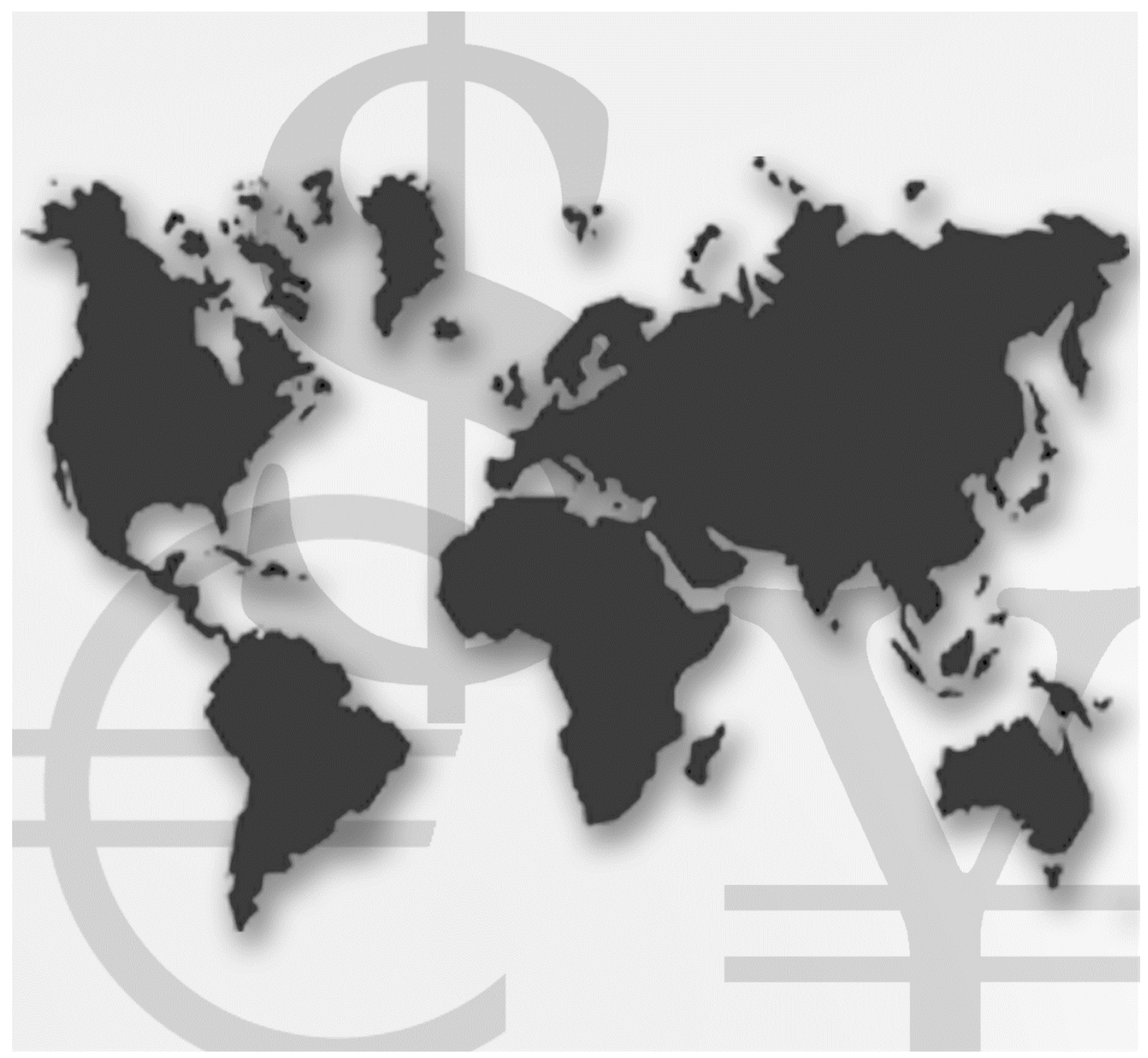

\section{International Finance Discussion Papers}

Board of Governors of the Federal Reserve System

Number 1144

September 2015 
Board of Governors of the Federal Reserve System

\author{
International Finance Discussion Papers
}

Number 1144

September 2015

International Dollar Flows

\author{
Ayelen Banegas \\ Ruth Judson \\ Charles Sims \\ Viktors Stebunovs
}

NOTE: International Finance and Discussion Papers are preliminary materials circulated to stimulate discussion and critical comment. References in publications to International Finance Discussion Papers (other than an acknowledgment that the writer has had access to unpublished material) should be cleared with the author or authors. Recent IDFPs are available on the Web at www.federalreserve.gov/pubs/ifdp/. This paper can be downloaded without charge from Social Science Research Network electronic library at www.ssrn.com. 
International Dollar Flows

\author{
Ayelen Banegas* \\ Ruth Judson\# \\ Charles Sims ${ }^{\dagger}$ \\ Viktors Stebunovs ${ }^{\ddagger}$
}

Abstract: Using confidential Federal Reserve data, we study the factors driving U.S. banknote flows between the United States and other countries. These flows are a significant component of capital flows in emerging market economies, where physical U.S. currency functions as a safe asset and precautionary demand for U.S. banknotes is a form of flight to quality. Prior to the global financial crisis, country-specific factors, including local economic uncertainty, largely explain the volume and heterogeneity of the flows. Since the crisis, global factors, particularly, global economic uncertainty, explain the flows markedly well. Further, precautionary demand for U.S. banknotes is not episodic.

Keywords: capital flows, currency flows, U.S. banknotes, safe asset, emerging market economies, economic uncertainty, flight to quality, capital flight, money demand.

JEL Classifications: F30; E40; E50.

* Board of Governors of the Federal Reserve System, 20th Street and Constitution Avenue, NW, Washington, DC 20551, U.S.A.; maria.a.banegas@frb.gov. URL: http://www. federalreserve.gov/econresdata/ayelen-banegas.htm.

\# Board of Governors of the Federal Reserve System, 20th Street and Constitution Avenue, NW, Washington, DC 20551, U.S.A.; rjudson@frb.gov. URL: http://www.federalreserve. gov/econresdata/ruth-a-judson.htm.

${ }_{\dagger}^{\dagger}$ Federal Reserve Bank of New York, 33 Liberty Street, New York, NY 10045, U.S.A.; charles.sims@ny.frb.org.

$\ddagger$ Board of Governors of the Federal Reserve System, 20th Street and Constitution Avenue, NW, Washington, DC 20551, U.S.A.; viktors.stebunovs@frb.gov. URL: http://www. federalreserve.gov/econresdata/viktors-stebunovs.htm.

The views in this paper are solely the responsibility of the authors and should not be interpreted as reflecting the views of the Board of Governors of the Federal Reserve System or of any other person associated with the Federal Reserve System. We are grateful for helpful comments to Carol Bertaut, Nicholas Bloom, Neil Ericsson, Stijn Claessens, Richard Porter, Patrice Robitaille, staff at the Federal Reserve Bank of New York Cash and Custody Function, and participants of seminars at the Federal Reserve Board and the 2014 International Cash Conference at the Deutsche Bundesbank. We thank Patrick Kennedy and Caleb Wroblewski for excellent research assistance. 


\section{Introduction}

Demand for U.S. dollars is driven by both domestic and international developments 11 Like the banknotes in other advanced economies, U.S. dollars tend to be used domestically as a medium of exchange. But, unlike the banknotes of most other advanced economies, U.S. dollars are extensively used far beyond the country's borders as a safe asset, particularly in emerging market economies, where conventional safe assets are not available. While banknotes are generally a small portion of cross-border financial flows - about 5 percent of net foreign private acquisitions of U.S. securities - for some countries in some years they can be substantial. For example, over the last decade and a half, net shipments of U.S. dollars to Argentina in some months exceeded a few percent of the country's annual GDP. More recently, in 2014, euros and U.S. dollar banknote shipments to Russia amounted to about $\$ 50$ billion, or about a third of the country's net capital outflows that year. In this context, for an emerging market economy, elevated, precautionary demand for U.S. banknotes is a form of flight to quality by its residents, which contributes to a broader capital flight.

Indeed, prior to the global financial crisis, episodes of unusually high demand for U.S. dollars, identified by elevated U.S. currency outflows from the United States, appeared to correspond to periods of economic or political crisis in specific countries or regions - for example, in Argentina or in the former Soviet Union. But, more recently, with the collapse of Lehman Brothers and the beginning of the global financial crisis, currency demand from abroad turned up sharply and, in contrast to earlier years, became broad-based rather than country- or region-specific.

In this paper, we study the factors driving demand for U.S. banknotes from abroad. We use a confidential data set of currency shipments by commercial banks between the United States and other countries, which is complied by the Federal Reserve. Our data set covers monthly payments and receipts - bilateral U.S. banknote flows between the United States and other countries - for a large number of countries from the mid-1990s to the present:2 Specifically, we analyze net shipments, defined as the difference between payments to and receipts from a country, in aggregate and for various country groupings over the last decade and a half: ${ }^{3}$ Net shipments cleanly identify demand for U.S. dollars because the supply of U.S. banknotes is perfectly elastic: The Federal Reserve supplies U.S. banknotes to commercial banks in a requested amount on a short notice $4^{4}$

\footnotetext{
${ }^{1}$ In this paper, "U.S. dollars" and "dollars" refers to physical banknotes rather than dollar-denominated assets. The vast majority of U.S. dollar banknotes in circulation (currently, about $\$ 1.3$ trillion, 11 percent of M2) are Federal Reserve notes.

${ }^{2}$ For example, net shipments are positive for a country that imports U.S. dollars and negative for a country that exports U.S. dollars.

${ }^{3}$ Although this data set begins in the late 1980s, we focus on the period from January 2000 to June 2013 because of limitations in data quality and coverage in the early part of the sample.

${ }^{4}$ Such a transaction also requires a payment of reserve balances to the Federal Reserve in the requested amount. Effectively, this is an exchange of cash for reserve balances. Conversely, the Federal Reserve also
} 
Building on the dollarization and capital flows literature, we explain net shipments with country-specific characteristics (past dollar use, local economic uncertainty, and local economic conditions) and global determinants (common shocks external to the country, such as global economic uncertainty) over the pre- and post-crisis periods. Because we emphasize the function of the U.S. dollar as a safe asset, we construct measures of local economic uncertainty using financial data and several measures of global economic uncertainty, which rely on financial market data and on Baker, Bloom, and Davis (2015) uncertainty indexes that are derived from U.S. and European news sources.

For net shipments in aggregate, our findings are consistent with those in the capital flows literature discussing determinants of broader capital flows (for example, Fratzscher (2012), Forbes and Warnock (2012), and Ghosh, Qureshi, Kim, and Zalduendo (2014)). Specifically, our regression analysis of net shipments in aggregate suggests that global factors that capture both financial risk and economic uncertainty predict U.S. banknote flows. In addition, these common factors have become increasingly important since the global financial crisis. While we rely on economic uncertainty indexes compiled from U.S. and European sources, we note that, by construction, they reflect U.S., European, and international events.5 To further strengthen the point that global uncertainty matters, we use a common component of economic uncertainty indexes for the United States and Europe in some regressions. Other global variables - in particular, typical determinants of money demand-play only a small role. We find mixed evidence on the explanatory power of macroeconomic indicators, such as global GDP growth and inflation..$^{6}$ Overall, at the aggregate level, our regression analyses indicate that global factors can explain significant amounts of variation in currency flows.

For our analysis of net shipments to countries grouped by the level of economic development or by the patterns of currency flows, we rely on a Hausman and Taylor (1981) specification that allows for including both country fixed effects and time-invariant country characteristics in a regression model. Our results also show that, since the global financial crisis, global economic uncertainty has an increasingly important role in explaining dollar flows, particularly to emerging market economies. The results also suggest a greater sensitivity of demand from abroad for U.S. banknotes to changes in economic uncertainty relative to changes in financial market stress. In addition, we find a large degree of heterogeneity across countries, with local factors such as inflation and global factors such as economic uncertainty having a larger effect on demand for U.S. banknotes in emerging market economies than in advanced economies. We show that mostly global factors explain flows to countries that do not use U.S. dollars but distribute them to other, less-developed regions and coun-

buys U.S. banknotes from commercial banks and, in exchange, pays them in reserve balances.

${ }^{5}$ Moreover, U.S. financial and economic developments may have international spillovers: For example, the 2013 taper tantrum resulted in substantial capital outflows from emerging market economies.

${ }^{6}$ Our findings show that there is no significant relationship between currency flows and the broad U.S. dollar index, oil prices, and gold prices. 
tries. These findings strongly support the narrative that U.S. dollars serve as a safe asset in emerging market economies but not in advanced economies. In contrast to the predictions of money demand theory, demand for U.S. currency appears to be interest rate or income growth insensitive. When we group countries based on the patterns of currency flows from abroad rather than the level of economic development, country-specific characteristics still predict dollar flows.

In the spirit of Forbes and Warnock (2012), we also evaluate the ability of local and global factors to explain low- and high-frequency components of currency flows. We find that the relationship between U.S. dollar flows and global uncertainty and other variables is present at a low frequency, but not at a high frequency. That is, we find that the relationship between global and local uncertainty and U.S. dollar flows is persistent rather than episodic. It may be that U.S. dollars, as a safe asset, provide hedging benefits on average rather just in times of stress. It may also be that times of stress are long-lasting, particularly in emerging market economies, leading to persistent demand for U.S. dollars. Indeed, in contrast to VIX, news-based uncertainty measures are very persistent, likely reflecting long crisis spells.

Our work is primarily related to two strands of the literature. First, the paper contributes to the capital flows literature that studies the dynamics and determinants of capital flows - for example, Calvo, Leiderman, and Reinhart (1993); Fernandez-Arias (1996); Chuhan, Claessens, and Mamingi (1998); and Griffin, Nardari, and Stulz (2004), who study the role of various factors determining capital flows. More recently, Fratzscher (2012) analyzes the role of common global shocks and country-specific characteristics on mutual fund flows during the crisis and the 2009-2010 recovery. Forbes and Warnock (2012) focus on episodes of extreme international capital flow movements and argue that global factors, such as global risk, are the main drivers of capital flow waves. Ghosh, Qureshi, Kim, and Zalduendo (2014) find that, for emerging market economies, global factors determine when surges of capital inflows will occur, but the amounts specific countries get are dependent on country circumstances.

We caution, though, that the comparison of our work with the literature is nuanced. While this strand of literature looks at capital flows and their determinants from a perspective of international investors investing in emerging market economies, we study demand for U.S. dollars as a safe asset from a perspective of residents of emerging market economies. While the literature finds that elevated global uncertainty leads to significantly lower capital flows to emerging market economies, we find that elevated local and global uncertainty boosts demand of residents of the affected countries for U.S. banknotes. The two mechanismsflight to quality by residents of the affected countries and capital flight by foreign investorsfunction in parallel, and both contribute to a worsening of the affected countries' capital accounts.

Second, the paper is related to the strand that studies the use of parallel or secondary 
currencies and constructs estimates of external U.S. dollar and euro circulation. Kamin and Ericsson (2003) is an example of the former and Judson (2012) of the latter 7 This strand of literature, however, does not explicitly recognize that the U.S. dollars functions as a safe asset in emerging market economies.

Our analysis has important implications for policy makers. From the perspective of foreign central banks, particularly those in emerging market economies, elevated demand for U.S. dollars is a form of flight to quality (by residents of these countries) that may result in substantial loss of official foreign exchange reserves. Hence, understanding and quantifying the factors affecting such demand is crucial for foreign central banks' operations, including determining a desired size of foreign exchange reserves. In this context, our novel findings is the increasing importance of global factors as determinants of currency flows for a given country $\left[^{8}\right.$

The remainder of this paper proceeds as follows. In the next section, we place our work in the context of previous studies on international capital flows and external U.S. dollar usage. In Section 3, we review the primary data sources and highlight some challenges of measuring international dollar flows. In Section 4, we present results for our set of aggregate regressions on the links between global factors and global demand for U.S. currency. In Section 5, we present results for our panel regressions and evaluate the ability of both global and country-specific factors to explain international currency flow dynamics. In Section 6 , we present a very brief overview of the significance of currency for Federal Reserve operations and policy making (and, in Appendix C, we construct a hypothetical estimate the effects of various trajectories for currency growth on the implementation of U.S. monetary policy). The final section concludes and provides some direction for future research.

\section{Place in the literature}

Currency flow data are highly confidential and are therefore largely unexplored in the literature, even though these flows are a significant component of capital flows for some countries. Hence, we rely mainly on two literature strands - on broader capital flows and on currency substitution - that appear related to our topic.

First, the paper contributes to the capital flows literature that studies the dynamics and determinants of capital flows. We build on previous work by Calvo, Leiderman, and Reinhart (1993), Fernandez-Arias (1996), Chuhan, Claessens, and Mamingi (1998), Griffin, Nardari,

\footnotetext{
${ }^{7}$ Other empirical studies include Doyle (2000), Judson and Porter (1996), Stix (2010), Fischer, Kohler, and Seitz (2004), Bartzsch, Rosl, and Seitz (2013), and Hellerstein and Ryan (2011), who use a portion of our data over an earlier period.

${ }^{8}$ Understanding the factors driving demand from abroad for U.S. dollars - a major contributor to U.S. currency growth - is also important for a wide range of Federal Reserve operational considerations and for the normalization of monetary policy, including potential large-scale liquidity draining operations and sales of securities from the Federal Reserve's System Open Market Account portfolio.
} 
and Stulz (2004) that study the role of various factors determining capital flows.9.$^{9}$ More recently, Fratzscher (2012) analyzes the role of common global shocks (push factors) and country-specific characteristics (pull factors) on global portfolio flows during the crisis and the 2009-2010 recovery. He finds that push factors such as global risk and liquidity had a significant effect on mutual fund flow dynamics, and that pull factors, including macroeconomic fundamentals, country risk, and institutional quality, can help explain the heterogeneity of portfolio flows across countries. Forbes and Warnock (2012) focus on episodes of extreme international capital flow movements - surges, stops, flights, and retrenchments - and argue that global factors, such as global risk, are the main drivers of capital-flow waves. They examine both capital inflows and outflows and find evidence that global risk is positively related to stops and retrenchments (decreases of gross inflows and outflows) and negatively correlated with surges and flights (increases of gross inflows and outflows). Also, they find that contagion through trade, proximity, and financial channels can be important factors explaining capital flow waves. In turn, Ghosh, Qureshi, Kim, and Zalduendo (2014) find that, for emerging market economies, global factors determine when surges of capital inflows will occur, but their magnitude and duration depend on country circumstances. Finally, Gourio, Siemer, and Verdelhan (2014) find for a large panel of emerging countries over the last few decades that aggregate stock market return volatilities - their measure of uncertaintyforecast capital flows. In particular, they find that when the stock market return volatility increases, capital inflows decrease and capital outflows increase, and that capital inflows respond to both systematic and country-specific shocks to volatility.

We note that the comparison of our work with this literature is nuanced. While this strand of literature tends to look at capital flows and their push and pull determinants from a perspective of international investors investing in emerging market economies, we study demand for U.S. dollars as a safe asset from a perspective of residents of emerging market economies. The literature finds that elevated global uncertainty leads to notably lower capital flows to emerging market economies. That is, this push factor discourages international investors from risk taking and curbs the supply of capital to these economies. In our work, elevated local and global uncertainty boosts demand of residents of the affected countries for U.S. banknotes. The two mechanisms - flight to quality by residents of the affected countries and capital flight by foreign investors - function in parallel, and both contribute to a worsening of the affected countries' capital accounts.

Second, the paper contributes to the literature that studies currency substitution, particularly the usage of U.S. currency abroad. Some studies analyze broad dollarization in post-hyperinflationary countries - for example, Kamin and Ericsson (2003) in Argentina. Other empirical studies estimate dollar circulation outside the United States, including Jud-

\footnotetext{
${ }^{9}$ Another strand of the capital flow literature looks at the effects of contagion on global flows - for example, Claessens and Forbes (2004), Forbes (2004), and Blanchard, Das, and Faruqee (2010).
} 
son (2012), Doyle (2000), and Judson and Porter (1996) 10 Recent estimates - for example, Judson (2012) - show that over a half of the value of U.S. currency in circulation is held abroad. Our priors, in part, are informed by Judson (2012), who finds that once a country or region begins using dollars, subsequent crises result in additional inflows, and that economic stabilization and modernization appear to result in reversal of these inflows. Hellerstein and Ryan (2011), who use a portion of our data (receipts of U.S. banknotes from commercial banks rather than net shipments) over an earlier period, find that historical peak inflation rates, international trade and trade barriers, and a degree of competition between the U.S. dollar and the euro as a secondary currency may explain shipments of U.S. banknotes from abroad to the United States.11

\section{Main data sources}

In this section, we discuss main sources and definitions of the data - in particular, of our main explained and explanatory variables.

\section{Cross-border flows of U.S. currency}

Data on cross-border flows of U.S. currency are available from two sources: U.S. Customs and the Federal Reserve. ${ }^{12}$ The source used in this analysis is the Federal Reserve data set, which is the richer, more informative of the two sources. It is a confidential, country-level data set that has been largely unexplored 13 The data set begins in the late 1980s and covers virtually every country in the world. It comprises monthly shipments of U.S. dollar banknotes between the United States and other countries. The Federal Reserve provides currency on demand to all account holders, including those who provide banknotes to international customers. Many of these institutions, including most of the largest wholesale banknote dealers, report, on a voluntary and confidential basis, the value and ultimate source or destination country of their receipts and payments of U.S. currency. The quality of the data varies across time as the set of reporting dealers has evolved; for all practical purposes, the data set begins in the mid-1990s. The level of detail in the reporting has generally improved over time as more dealers have begun to report, and reporting dealers account for

\footnotetext{
${ }^{10}$ For examples of such estimates for euro usage, see Stix (2010), Fischer, Kohler, and Seitz (2004), and Bartzsch, Rosl, and Seitz (2013).

${ }^{11}$ We consider net flows rather than gross flows to be a better indicator of demand from abroad for U.S. currency. Consider a country for which U.S. dollar receipts are zero but U.S. dollar payments are large. Based on Hellerstein and Ryan (2011)'s approach, this country experiencing flight to quality will be wrongly excluded from analysis. Separately, note that one may still see some receipts from that country in the data, likely because worn banknotes have to be replaced.

${ }^{12}$ U.S. currency exports, like other exports, figure in the U.S. balance of payments and international investment position. The U.S. Customs data are described in Appendix A.

${ }^{13}$ The aggregate data, however, have been used in previous work; see, for example, Judson and Porter (1996) and Judson (2012). Hellerstein and Ryan (2011) use only a portion of data at the country level.
} 
the vast majority of the reporting in this data set in the sample period. While not all banks that deal in the international shipment of banknotes provide these reports, the banknote shipping business is highly concentrated, and this data set over our sample period from 2000 to 2013 captures the vast majority of banknote shipments that cross U.S. borders through commercial banking channels.

Cross-border flows of U.S. currency can take place through nonbank channels as well. U.S. Customs data may capture some of these flows, but these data are unreliable and cannot be used to identify either an ultimate origin or an ultimate destination of currency flows 14 There is some evidence that, for some countries, these nonbank flows of a certain direction may be significant. Indeed, observations gathered in the course of the joint U.S. Treasury-Federal Reserve International Currency Awareness Program (ICAP) indicate that several countries receive dollar inflows through nonbank channels such as tourists or migrants but return the currency to the United States through banking channels. In part to address such issues, we explain net shipments of U.S. currency in our analysis.

\section{Global and local uncertainty}

Because we emphasize the function of the U.S. dollar as a safe asset, we construct several measures of local and global economic uncertainty, which rely on financial market data and on Baker, Bloom, and Davis (2015) uncertainty indexes that are derived from U.S. and European news sources.

Baker, Bloom, and Davis (2015) develop an index of economic policy uncertainty that draws on the frequency of U.S. newspaper references to policy uncertainty and other indicators. The index spikes around events both in the United States and abroad, such as the Lehman Brothers bankruptcy and the intensification of the European debt crisis in 2011. Baker, Bloom, and Davis (2015) show that a significant dynamic relationship exists between their economic policy uncertainty index and real macroeconomic variables for the United States. At the macro level, positive innovations in the index foreshadow declines in investment, output, and employment in the following months. At a micro level, in regressions that study uncertainty effects on firm-level investment and employment and that include both the VIX and the uncertainty index, only the latter has negative and statistically significant effects.

Baker, Bloom, and Davis (2015) construct their index from three types of underlying components, with varying degrees of importance for our work. The first component, which is the most crucial for us, quantifies newspaper coverage of policy-related economic uncertainty. The second component reflects the number of federal tax code provisions set to expire in future years. The third component uses disagreement among economic forecasters as a proxy

\footnotetext{
${ }^{14}$ See Appendix A for details.
} 
for uncertainty. While the second and third components are arguably U.S.-centric, the first component captures uncertainty about events in both the United States and abroad 15

With the first component, Baker, Bloom, and Davis (2015) seek to capture uncertainty about who will make economic policy decisions; what economic policy actions will be undertaken and when; the economic effects of past, present, and future policy actions; and uncertainty induced by policy inaction. They also want the component to capture economic uncertainty related to national security concerns and other policy matters that are not mainly economic in character. They base this component on search results from 10 leading U.S. newspapers that tend to cover domestic and international developments. ${ }^{16}$ In particular, they identify articles containing "uncertainty" or "uncertain," "economic" or "economy," and one or more of the following terms: "congress," "deficit," "Federal Reserve," "legislation," "regulation," or "White House." In other words, to meet their criteria the article must include terms in all three categories pertaining to uncertainty, the economy, and policy. Note that many of these terms can capture international developments as well as international spillovers from U.S. developments - developments that contribute to economic uncertainty in the United States and elsewhere. For example, the 2013 taper tantrum surprised financial markets with the possibility of an early interest rate hike by the Federal Reserve and led to significant capital outflows from emerging market economies, likely worsening their economic prospects.

The uncertainty indexes for other countries are constructed in a similar fashion using foreign news sources. Out of all available indexes, we focus on the European index, and we later derive principal components of the U.S. and European indexes and other variables to have a measure of "true" global economic uncertainty. ${ }^{17}$

Because the indexes of Baker, Bloom, and Davis (2015) are available for only a very limited number of emerging market economies for a short period of time, we construct proxies for local, country-specific uncertainty based on stock markets' volatility for two reasons. First, as Baker, Bloom, and Davis (2015) point out for the United States, since 2008, an increasingly large share of large stock-market movements have been caused by

\footnotetext{
${ }^{15}$ The second component of their index draws on reports by the Congressional Budget Office that compile lists of temporary federal tax code provisions. The third component of their policy-related uncertainty index draws on the Federal Reserve Bank of Philadelphia's Survey of Professional Forecasters. It is possible that uncertainty about U.S. economic policy developments feeds uncertainty about global economic developments. Hence, in our work, we use the overall index rather than its components.

${ }^{16}$ Baker, Bloom, and Davis (2015) base their index on news reported in USA Today, the Miami Herald, the Chicago Tribune, the Washington Post, the Los Angeles Times, the Boston Globe, the San Francisco Chronicle, the Dallas Morning News, the New York Times, and the Wall Street Journal. They revised the choice of newspapers in 2013, shifting the list toward more domestically oriented publications. In part, this revision explains why our sample ends in mid-2013.

${ }^{17}$ The construction of the European index is similar to that of the U.S. version but does not include a component reflecting upcoming tax code expirations. For this index, dispersion is measured with respect to forecasts made for the economies of Britain, France, Germany, Italy, and Spain. Appendix B provides a detailed explanation of these factors.
} 
policy-related events. Second, as Gourio, Siemer, and Verdelhan (2014) find for a large panel of emerging market economies over the last 40 years, aggregate stock market return volatilities, their measure of uncertainty, forecast capital flows. That is, when the stock market return volatility increases, capital inflows decrease and capital outflows increase.

\section{Empirical strategy and results}

From the ICAP findings and the literature, we know that U.S. dollars are extensively used far beyond the U.S. borders as a safe asset, particularly in emerging market economies, where conventional safe assets are not available. In these countries, U.S. currency might be the ultimate safe asset for several reasons. First, it is backed by high-quality securities in the Federal Reserve's System Open Market Account portfolio, such as U.S. Treasury securities. Second, it is highly liquid in many economies where users are familiar with it. Third, it is not considered vulnerable to devaluation through either high inflation or substantial exchangerate depreciation. Finally, it can serve as a store of value and medium of exchange even in the absence of a well-developed financial system. Indeed, the ICAP interviews found that economic and political uncertainty were the most commonly mentioned factors driving international dollar usage. In this context, elevated demand for U.S. banknotes is a form of flight to quality by residents of an affected country, which may contribute to a broader capital flight. Conversely, subdued demand indicates the opposite of such a phenomenon.

For the identification of demand for U.S. banknotes from abroad or from a given country, we take advantage of the institutional details of the supply of U.S. banknotes: We rely on reports of currency dealers for destinations of currency shipments. Conversely, we rely on reports of origins of currency shipments when the Federal Reserve buys the U.S. dollars back. We focus on net shipments, which are defined as shipments of currency from the United States to other countries (payments) less shipments of currency from other countries to the United States (receipts). We note that net shipments cleanly identify demand for U.S. dollars because the supply of U.S. banknotes is perfectly elastic: The Federal Reserve supplies (or buys back) U.S. banknotes to (from) commercial banks in a requested amount on a short notice.

In this section, we first model net shipments in aggregate. Second, we model net shipments to countries grouped by the level of their economic development or by the patterns of currency flows. In all cases, we keep a consistent set of explanatory variables.

\section{Aggregate regressions}

To quantify the link between U.S. currency flows and economic, financial, and political developments, we estimate the relationship between net shipments of U.S. currency notes overseas to all locations and various global and regional measures of risk and uncertainty. 
Intuitively, since U.S. dollar notes are extensively used abroad as safe assets, we expect international demand for U.S. dollars to be stronger during periods of higher economic and political uncertainty. In addition to our analysis of risk and uncertainty measures, we evaluate the contribution of global macroeconomic factors in explaining net U.S. currency flows. Indeed, as shown in Figure 1, net shipments in aggregate peaked in late 1999, in mid-2001, in late 2008, and most recently in March 2014, coinciding with the Y2K problem, a crisis in Argentina, the collapse of Lehman Brothers, and, most recently, the events in Ukraine 18

We first investigate the explanatory power of the most widely used proxies for financial market volatility in developed markets and sovereign default risk in developing countries. Our baseline regression can be summarized as follows:

$$
Y_{t}=X_{t} \beta+\epsilon_{t}
$$

where $t$ indexes time; $Y_{t}$ denotes net shipments of U.S. currency overseas to all locations in billions of U.S. dollars; $X_{t}$ is a set of global and regional macroeconomic, financial, and uncertainty-related variables; and $\epsilon_{t}$ is an error term (in estimation, we use a heteroskedasticityrobust variance estimator). Specifically, we consider the Chicago Board Options Exchange Market Volatility Index, or VIX - a measure of the short-term expectation of the U.S. stock market volatility - as a measure of risk in the developed world, and the J.P. Morgan Global Sovereign Spread index, or EMBI, as a proxy for sovereign default risk of developing countries.

Table 1 shows descriptive statistics for the dependent variable, which is not seasonally adjusted. Over the period from January 2000 to June 2013, net shipments per month averaged nearly $\$ 800$ million with a standard deviation of about $\$ 3$ billion. The differences between the pre- and post-crisis periods are striking: Net shipments in the latter period were an order of magnitude larger and more volatile.

Table 2 reports the results for our set of baseline regressions using different measures of risk and global macro variables. As shown in Column 1 of Table 2 , the explanatory power of the regression, summarized by the adjusted $R^{2}$, is quite low, at 9 percent. Furthermore, our robustness analysis indicates that this result is driven by the two observations corresponding to the outbreak of the financial crisis, September and October 2008. When we exclude these two observations from the sample, both the VIX and the EMBI lose their statistical significance.

The lack of explanatory power of these standard measures of volatility motivates us to explore alternative measures of uncertainty. The choice of alternatives is, in part, inspired by Baker, Bloom, and Davis (2015), who find that their uncertainty index is better at explaining

\footnotetext{
${ }^{18}$ We have not been able to identify seasonal patterns in the series.
} 
economic activity than the VIX. Specifically, we evaluate alternative sources of risk related to the real side of the economy such as the uncertainty indexes for the United States and Europe compiled by Baker, Bloom, and Davis (2015).

As shown in Column 2 of Table 2, these indexes prove to be helpful predictors of U.S. currency flows and improve significantly the fit of our regression, with the adjusted $R^{2}$ increasing to about 40 percent. In particular, our results suggest that periods of higher economic uncertainty are associated with higher demand for U.S. banknotes abroad.19 Strong currency growth during the financial crisis of 2008 and the subsequent European debt crisis in 2011 support these findings; see Figure 11. This finding is not driven by shipments to a particular country or a region, as Figure 2 demonstrates. The figure shows annual commercial shipments of currency for two periods (2001-August 2008 and September 2008 to 2013) and for two sets of countries, Russia and Argentina (the red bars) and all other countries (the gray bars). In the most recent period, shipments to Russia and Argentina were higher, but, more remarkably, shipments to all other countries swung from being negative, on net, to being strongly positive and significantly larger than the shipments to Argentina and Russia. This finding is also not driven by an episodic relationship between net shipments and economic uncertainty, as indicated by Figure 3, which shows a scatter plot of the uncertainty index and net currency shipments, with observations from the pre-crisis and crisis periods clearly marked. As for the economic significance of the results, note that for the sample period, the uncertainty indexes have a mean of about 100 and standard deviation of about 40. Thus, a one standard deviation move in one index alone is associated with an increase in shipments of about $\$ 1.2$ billion; a simultaneous increase in both indexes is associated with an increase of about $\$ 2.4$ billion in monthly shipments.

The last financial crisis provided evidence of stronger co-movements among financial markets in advanced economies. For example, episodes centered in the United States were immediately discounted in European asset prices, and vice versa.

To allow for these correlations and to further sharpen the focus on economic uncertainty and financial stress as determinants of U.S. dollar flows, we use principal component analysis ${ }^{20}$ We extract factors from standardized versions of four inputs: month-average values of the VIX and VSTOXX indexes, and the monthly U.S. and European economic policy uncertainty indexes. ${ }^{21}$ These series were chosen as proxy measures of market stress and economic policy uncertainty in the United States and advanced Europe. The first principal component (PC), market stress and policy uncertainty, replicates the shared variance of the four inputs,

\footnotetext{
${ }^{19}$ The results are robust to the exclusion of U.S. dollar flows to Argentina and Russia from total net shipments as well as to the exclusion of observations for September and October of 2008.

${ }^{20}$ The factor loadings are elements of eigenvectors obtained from the covariance matrix of the input series. A positive (negative) factor loading for input series i with respect to principal component $\mathrm{j}$ indicates positive (negative) correlation between that input series and principal component.

${ }^{21}$ The VSTOXX index, like the VIX, is not very correlated with shipments on its own, but we include it here in order to capture European equity volatility.
} 
which represents approximately 70 percent of total variance across the four standardized series. The second component (policy uncertainty vs. market stress) tracks differences between co-movements of the economic policy uncertainty indices and co-movements of the two market stress proxies, and thus can be used to distinguish between the effects on currency demand of changes in economic policy uncertainty relative to market stress. Analogously, the third PC (U.S. factors vs. European factors) can be used to distinguish between the effect of changes in U.S. factors relative to changes in European factors. ${ }^{22}$ Table 3 lists the factor loadings for the three principal components, the signs and magnitudes of which indicate the nature of the correlations between the factors and the four series from which they were extracted.

As shown in Column 3 of Table 2, the three principal components prove to be helpful in explaining currency flows. The positive and statistically significant estimate of the first PC suggests that higher economic and market-related uncertainty in the United States and Europe is related to stronger currency flows. The second PC points to a greater sensitivity of international currency flows to changes in economic policy uncertainty factors relative to changes in market stress in the United States and Europe. Similarly, estimates for the third PC indicate that changes in U.S. economic uncertainty and market stress will have a greater impact on international demand for U.S. currency than changes in European uncertainty factors. That is, currency flows appear to be more sensitive to U.S. events than to European developments. The principal components are constructed to have mean zero and standard deviation one, so a one standard deviation increase in each principal component is associated with an increase of about $\$ 1$ billion in monthly shipments.

Building on these results, in Column 4 of Table 2 we expand our set of covariates and include a group of widely used global macro factors that have been identified in the literature as potential drivers of demand for U.S. banknotes. Specifically, we evaluate the performance of global GDP growth, global inflation, the broad U.S. dollar index, oil prices, and gold prices. Whereas estimates for the principal components remain positive and statistically significant, we find no explanatory power of the set of global macroeconomic indicators. These growth rates are expressed in annual percentages (for example, 5 percent annual GDP growth would have a value of five) ${ }^{23}$ Thus, for example, a one percentage point drop in global GDP growth is associated with an increase in monthly shipments of $\$ 110$ million.

As noted previously, and as illustrated in Figures 1 and 2, we conjecture that the factors driving international demand for U.S. currency might have changed in 2008. As Baker, Bloom, and Davis (2015) point out, policy uncertainty, as measured by their index, are at extremely elevated levels compared with recent history. Since 2008, economic policy uncertainty has averaged about twice the level of the previous two decades. Based on these

\footnotetext{
${ }^{22}$ Appendix B provides an explanation of these factors.

${ }^{23}$ Adding lags did not produce markedly different results.
} 
simple observations about aggregate shipment patterns beginning in late 2008, we further investigate the role of global uncertainty and macro factors by evaluating their explanatory power in the pre-crisis and crisis periods. To preview the results, we find strong evidence that suggests that global factors have become important drivers of international currency flows since the most recent financial crisis.

In Table 4, we begin with the same regression as in the last column of Table 2. In Column 2, we split the sample into two periods: the "pre-crisis" period (January 2000 to August 2008) and the "crisis" period (September 2008 to the end of the sample period). ${ }^{24}$ The market stress and policy uncertainty PC, our proxy for global economic and market uncertainty, proves to be economically and statistically significant throughout the different regression specifications during the crisis period starting in the fourth quarter of 2008. The second PC points in the same direction, with coefficients being positive and statistically significant during the crisis period. Furthermore, whereas the full sample results provide no evidence of the value of global macroeconomic factors as predictors of currency demand, the results in the third column show that global macro variables such as the broad U.S. dollar index, oil prices, and global inflation are statistically and economically significant during the crisis period. Conversely, global GDP growth appears to be a helpful predictor of currency flows during the pre-crisis period. The negative coefficient indicates that periods of global economic growth are associated with a decrease in total net shipments of U.S. currency notes.

Overall, our aggregate regression analysis provides novel insights into the determinants of U.S. currency flows. In particular, our results suggest that, over recent years, global uncertainty and global macroeconomic factors have become increasingly important determinants of international demand for U.S. currency. ${ }^{25}$ To clarify the strength of the uncertainty results, particularly in the crisis period, we consider Baker, Bloom, and Davis (2015)'s measures of economic policy uncertainty, sourced from U.S. and European newspapers. By construction, these measures reflect both domestic and international events that have bearing on economic uncertainty. Moreover, U.S. financial and economic developments tend to have international spillovers.

\section{Panel regressions}

In this section, we build on our aggregate regression analysis and examine the relationship between currency flows and local and global factors using data at the country level. ${ }^{26}$

\footnotetext{
${ }^{24}$ While in some cases it might be necessary to use statistical tests to identify the break between two periods, in this case the turning point is clear. It is fairly easily discerned in Figure 1, and it is quite obvious in Figure A1 in Appendix C, where the sharp turn in the red line, for the year 2008, marks the shift.

${ }^{25}$ The results are robust to the exclusion of U.S. dollar flows to Argentina and Russia from total net shipments as well as to the exclusion of observations for September and October of 2008; these results are available on request.

${ }^{26}$ The data set does not cover U.S. banknote flows between other countries, which may be substantial in some cases - for example, in areas where large volumes of cross-border trade are conducted in cash. The
} 
Using a panel data approach, we can examine the effects of country-specific characteristics and developments on demand for U.S. dollars. As noted earlier, the shipments data set contains data for nearly every country in the world. However, as a practical matter, we focus on a subset of about sixty countries for which shipments over time have been non-negligible. Of that set of countries, we were able to obtain quarterly or monthly data on income growth, inflation, exchange rates, and equity market volatility for over 40 countries, which are the subject of our analysis.

Our sample consists of nearly 7,000 country-month observations from January 2000 to June 2013 for a group of 42 countries - 19 advanced economies, 17 emerging market economies, and 6 currency hubs. In addition to the variables introduced in the aggregate regressions, we include country-specific factors that the literature suggests may explain capital flows: financial market risk; local inflation; foreign exchange reserve growth; and a measure of cumulative net flows, which is defined as cumulative shipments until 2000 scaled by PPP-adjusted GDP in 1999. Our financial market risk factor is a measure of realized equity market volatility and is constructed as the monthly variance of the daily growth rates of the local equity index. Intuitively, we would expect that higher uncertainty in local financial markets will be associated with higher demand for U.S. currency. We include local inflation as a regressor because inflationary episodes have often been associated with increased dollar usage. Also, we consider local foreign exchange reserve growth rates and past cumulative net shipments, which can be interpreted as a measure of the country's historical experience with U.S. dollar flows. Initially, we also included variables that are often cited as determinants of money demand, such as interest rates and industrial production (a proxy for income), but these variables had no statistically significant effect and were therefore dropped. Finally, in order to make the units comparable across countries, we define our dependent variable as the ratio of net shipments to GDP. More precisely, we annualized monthly net shipments and scaled them by annual GDP in U.S. dollars, then expressed the ratio in basis points.

We explore three approaches to estimating a panel model: the random-effects estimator, the fixed-effects estimator, and Hausman and Taylor (1981)'s estimator. The difference between the random-effects model and the fixed-effects model is based on assumptions about the correlation between the individual-specific effects and the set of regressors. In addition, in cases where it is more reasonable to assume that the individual effects are related to the regressors, estimation of time-invariant explanatory variables is not possible. To address these issues, Hausman and Taylor (1981) introduced a model where some of the explanatory variables - observed, time-invariant covariates - are related to the unobserved, individual-specific effects, while others are not. The Hausman-Taylor estimator is consistent

absence of such data does not affect aggregate measurements of commercial bank currency shipment flows into and out of the United States. Moreover, worn U.S. banknotes eventually get shipped to the United States to be replaced, and, hence, will show up in the country-level data. 
and efficient, does not require any external instruments, and, in contrast to the fixed-effects estimator, allows estimating coefficients for time-invariant variables.

Based on specification testing (not shown), we settle on a Hausman and Taylor (1981) estimator. Formally, our set up can be summarized as follows:

$$
y_{i, t}=X_{i, t} \beta+Z_{i} \eta+\alpha_{i}+\epsilon_{i, t}
$$

where $i$ indexes countries, $t$ indexes time, and $y_{i, t}$ is the ratio of net shipments to GDP; $X_{i, t}$ is the set of country-specific and global predictors; $Z_{i}$ is the individual past (time-invariant) cumulative shipments; $\alpha_{i}$ is the country fixed effect with mean zero and variance $\sigma_{\alpha}^{2}$; and the term $\epsilon_{i, t}$ stands for i.i.d. errors. Further, $X_{i, t}$ comprises the set of exogenous covariates, including the principal components uncertainty factors introduced in Table 3 , and the set of country-specific covariates, including foreign exchange reserve growth. $Z_{i}$ and the latter set are the endogenous variables in the system due to their correlation with $\alpha_{i}{ }^{27}$

Based on the results of the aggregate regressions, we move directly to a specification with separate coefficients for the pre-crisis and crisis periods, as defined earlier.

\section{Results for countries grouped by the level of economic development}

In addition to our observations about the break in the time series in September 2008, country-level shipment patterns and the knowledge gathered through the ICAP suggest that the relationship between currency flows and global and local variables might be different for different countries. We identify several groups of countries based on the level of their economic development (emerging market economies (EMEs) and advanced economies (AEs)) and their function in the distribution of U.S. banknotes (currency hubs (hubs) and all other countries ("AllxHubs"). Table 5 lists of the countries in each group.

Table 6 shows descriptive statistics of the scaled net shipments to countries grouped by the level of economic development and function in the distribution of U.S. currency. It is immediately clear that net shipments to hubs are very different from those to all other countries. They are negative, large in absolute magnitude, and very volatile. While average flows to emerging market economies and advanced economies are comparable in size, they are an order of magnitude more volatile. As for the economic significance of net shipments, we provide an example for Argentina - a country that discloses such shipments, hence these data are not subject to confidentiality. Net shipments to Argentina averaged about $\$ 500$ million a month over the sample period. Hence, the annualized average shipments of $\$ 6$ billion represents about 2 percent of the country's annual GDP, a substantial percentage.

\footnotetext{
${ }^{27}$ We opted not to include country-specific characteristics, such as levels of financial development or measures of capital controls as constructed in Chinn and Ito (2006), because they vary very little over our sample period and cannot be clearly distinguished from country fixed effects. We note, though, that past cumulative shipments may be correlated with some of the country-specific characteristics.
} 
Regression results by country group are reported in Table 8 , with the results for the full panel in Column 1. ${ }^{28}$ The results for the full panel are broadly similar to the aggregate results and in line with our expectations, though there are a few exceptions. As in the aggregate regressions, the measures of global uncertainty are positive and statistically significant for the first two factors during the crisis period, but are statistically insignificant in the pre-crisis period. Country-specific estimates for equity market volatility and inflation are positive and statistically significant for both periods in the full panel. ${ }^{29}$ However, while the economic significance of local financial market volatility appears stronger in the pre-crisis period, domestic inflation plays a larger role in explaining currency flows in the crisis period. Also, cumulative net shipments, our measure of the country's historical experience with U.S. dollar flows, is positive and statistically significant. Conversely, we find a negative relationship between foreign exchange reserve growth and currency flows. ${ }^{30}$

The full panel regression combines countries whose experiences with, and uses of, dollars are quite disparate. As a result, some of the effects of the predictors on currency flows might go in opposite directions or even cancel out when pooling the data. To account for this issue and to gain a better understanding of currency flows dynamics in the next regressions, we examine these relationships for groups of countries that we expect to be more homogenous, either because of their level of development, their role in the distribution system for dollars, or their position as a net importer or exporter of dollars. Column 2 in Table 8 reports regressions estimated just for emerging market economies. For these countries, the isolated global uncertainty component is statistically significant, and only in the crisis period. As for the local predictors, the coefficients for equity-market volatility and inflation are positive and statistically significant in both periods, while foreign exchange reserve growth is negative and statistically significant during the pre-crisis period. Notably, the $R^{2}$ for this group of countries is considerably higher, at nearly 60 percent. Our robustness checks (not shown) suggest that these results are driven by shipments to either Eastern Europe or the former Soviet Union.

Column 3 of Table 8 reports results for advanced economies. In general, dollar usage in these countries appears to be minimal and limited to tourism. Not surprisingly, coefficient estimates are generally small in magnitude; relatively few are statistically significant; and the $R^{2}$ is quite low, at about 25 percent. Column 4 reports results for a group of countries

\footnotetext{
${ }^{28}$ We exclude hubs - for example, Austria and the United Kingdom-from the full panel regressions, as their demand for U.S. currency can be expected to be uncorrelated with the country's fundamentals. While they are home to large banknote retailers and major international airports, there is little evidence of domestic use of dollars. The full panel results are robust to the inclusion of hub countries in the panel.

${ }^{29}$ The differences between the coefficient estimates in the two periods are statistically significant at the 10 percent level.

${ }^{30}$ Exclusion of this variable does not affect our results. Recall that elevated demand for U.S. dollars is a form of capital flight (by residents of these countries), and it appears to result in loss of official foreign reserves.
} 
that appear to function largely as distribution centers for currency. For these countries, there is little evidence of domestic use of dollars; at the same time, they are home to large banknote retailers and major international airports. Information gathered during the ICAP project indicated that most of the dollars shipped to or from these countries had come from third countries. Coefficients on local inflation and the second principal component factor that isolates global uncertainty from market stress are significant for these countries.

Results for countries grouped by the patterns of currency flows

We identify several groups of countries based on the patterns of currency flows: countries with large flows of U.S. banknotes in either direction (Big), countries with large positive inflows (BigNetPos), countries with large negative outflows (BigNetNeg), countries with persistent inflows (NetPos), and countries with persistent outflows (NetNeg). Table 5 lists of the countries in each group.

Table 7 shows descriptive statistics for net shipments to countries grouped by the patterns of currency flows. Net shipments for "Big" countries average to about zero because roughly half of these countries receive large shipments of U.S. banknotes, while the other half ship U.S. banknotes to the United States in similar quantities. Countries that tend to have large inflows of U.S. currency received, on average, roughly similar amounts in the pre- and postcrisis periods. However, countries that tend to have large outflows of U.S. currency shipped to the United States, on average, slightly lower amounts in the post-crisis period.

Results for panel regressions based on these criteria are shown in Table 9. Column 1 shows the results for the full sample, as in Table 8. The following columns group the countries into those that have shown large shipments relative to GDP and overall ("Big"), those which shipments are positive overall ("NetPos"), those which shipments are both large and positive ("BigPos"), and the same for negative net shipments ("NetNeg" and "BigNeg"). In these results, local equity market volatility is consistently positive and statistically significant in the pre-crisis period but not in the crisis period. Local inflation is nearly always statistically significant and positive in both periods. Measures of uncertainty are more strongly and consistently positive and statistically significant during the crisis period.

\section{Economic significance}

Figure 4 summarizes the contributions to net currency shipments of local variables (the red bars) and global variables (the blue bars) over the pre- and post-crisis periods based on the regression results Tables 8 and 9. (Recall that we annualized monthly net shipments scaled by annual GDP in U.S. dollars, and expressed the ratio in basis points.) As panel 1 shows for all countries excluding hubs ("AllxHubs"), the contributions of global factors were negative prior to the crisis (about -30 basis points) but slightly positive during the 
post-crisis (a few basis points); local variables appeared to have about the same contribution in both periods (about 40 basis points). Across countries grouped by their economic development or function in currency distribution, the contribution of global factors changed sign and increased in magnitude over time, especially in emerging market economies (panel 2) and currency hubs that tend to supply U.S. dollars to emerging market economies (panel 4). While we observe a similar pattern for advanced economies, we should note that the magnitudes of the contribution of global factors are small. This finding does not indicate that U.S. dollars function as a safe asset in these countries, but rather suggests that these countries may have functioned like currency hubs. Across countries grouped by the patterns of currency flows, for countries where dollar usage is substantial - for example, those in the "BigPos" group, which includes Russia, Ukraine, and Kazakhstan - we observe patterns and magnitudes similar to those for emerging market economies.

\section{Low- and high-frequency results by country groups}

As indicated earlier, economic or political crises in specific regions or countries coincided with episodic increases in net currency shipments to destinations such as Argentina and the former Soviet Union, so it might be reasonable to suppose that the impact of global risk and economic uncertainty is also episodic. In the spirit of Forbes and Warnock (2012), we evaluate the ability of both local and global factors to explain both low- and high-frequency components of currency flows. After all, banknote flows are the physical component of financial capital flows. Since the demand for U.S. currency abroad stems from its use as a safe asset, net currency shipments may exhibit behavior similar to international capital flows during periods of increased global risk. As discussed earlier, elevated precautionary demand for U.S. banknotes is a form of capital flight out of the affected country.

We test this possibility by isolating low-frequency and high-frequency components of the shipments data using the band pass filter developed by Christiano and Fitzgerald (2003) ${ }^{31}$ We estimate high-frequency components corresponding to periods of up to 12 months and low-frequency components corresponding to periods of no less than 12 months ${ }^{32}$ Seasonal fluctuations were therefore included in the high-frequency component along with transitory fluctuations. An examination of the data indicates that seasonal fluctuations are negligible for most cross-sections, and the high-frequency components therefore primarily reflect transitory fluctuations that would include episodic increases and decreases lasting up to a year ${ }^{33}$

\footnotetext{
${ }^{31}$ The band pass filter is "asymmetric," meaning that the weights applied to observations at times $t+q$ and $t-q$ in the estimation of the filtered component at time $t$ are not necessarily the same. We chose this filter because it allowed us to estimate frequency components for our entire data set, whereas the use of a symmetric filter would have resulted in a meaningful loss of data through truncation.

${ }^{32}$ In Forbes and Warnock (2012), surges of various types last, on average, between three and four quarters. This difference in choice of frequency threshold and the differences in frequency decomposition methods make our and their results not directly comparable.

${ }^{33}$ The use of asymmetric weights produces phase shifts in the filtered components that can cause fluctua-
} 
The low-frequency components reflect more persistent phenomena.

As shown in Tables 10 and 11, the results of regressions using low-frequency components were broadly similar to those estimated on unfiltered net shipments. The magnitudes of the coefficient estimates for the two global risk principal components were typically smaller when low-frequency components were used, likely because of the reduced variances of the dependent variables ${ }^{34}$ Although smaller in magnitude, most of the coefficients obtained from the low-frequency regressions had the same signs as those obtained from regressions using the unfiltered data, and most of the coefficients that were statistically significant when the unfiltered data were used were also significant when the low-frequency components were used. These results suggest that the relationship between global uncertainty and currency flows is persistent rather than episodic. It may be that U.S. dollars, as a safe asset, provide hedging benefits on average rather just in times of stress. It may also be that times of stress in emerging market economies are long-lasting, leading to persistent demand for U.S. dollars. Indeed, in contrast to VIX, news-based uncertainty measures are very persistent, likely reflecting long crisis spells.

We omit the results for high-frequency components because of the general absence of their statistical significance. Foreign exchange reserves are the only variable that appears to have robust negative correlation with the flows for emerging market economies and countries with large inflows of U.S. banknotes, but their explanatory power is extremely low. In addition, the correlation may be, to some extent, mechanical.

\section{Implications of currency demand from abroad for the Federal Reserve's operations}

Understanding the demand for currency has consistently played an important role in Federal Reserve operations, both in the implementation of monetary policy and in the logistical planning needed to supply banknotes of high quality in adequate quantities. ${ }^{35}$ From the 1990s until late 2008, the Federal Reserve targeted the federal funds rate by adjusting the supply of reserve balances, in part to offset changes in demand for currency (which add

tions that are unsynchronized with fluctuations in the raw data. We looked for evidence of significant phase shifts by calculating cross correlations between the raw data and the low-frequency components at leads and lags of up to 36 months. If filtering had resulted in significant shifts, the misalignment of fluctuations would have resulted in higher correlation of the raw data to leads or lags of the low-frequency components than to the contemporaneous components. For each cross-section in our data set, the raw data were more highly correlated to the contemporaneous low-frequency components than to components at any lead or lag, which suggests that phase shifts were negligible.

${ }^{34}$ By removing the high-frequency components, we left less variance to be explained by the regressors. For most of the countries in our sample, removal of the high-frequency components reduced variance by 25 to 40 percent. $R^{2}$ values for the low-frequency regressions were higher despite the smaller magnitudes of the regression coefficients, suggesting that the primary reason for the smaller coefficient estimates was the reduced variances of the dependent variables rather than a deterioration in the quality of the goodness of fit.

${ }^{35}$ For more details, see Board of Governors of the Federal Reserve System (2006). 
or drain reserve balances). At that time, currency in circulation was the primary liability on the Federal Reserve's balance sheet (shown in green in Figure 5) and changes in currency demand were a major consideration in the conduct of daily open market operations as well as in longer-range planning related to the Federal Reserve's System Open Market Account portfolio 36

After late 2008, deposits of depository institutions at the Federal Reserve (that is, reserve balances in the banking system), shown in gray, increased significantly, and they now greatly exceed currency as the largest liability on the Federal Reserve's balance sheet. Projected currency growth nonetheless remains an important input into planning for the Federal Reserve's exit from its current asset purchase programs and, ultimately, balance-sheet normalization. In particular, in the case of normalization, the higher the currency growth, the more reserve balances are drained by this autonomous factor. This increase in currency in circulation reduces the quantity of U.S. Treasury securities that the Federal Reserve needs to sell to reduce the size of its balance sheet. In addition, in the process, the Federal Reserve will spend less on remuneration of reserve balances and, hence, will remit more to the U.S. Treasury. We work out such an example in Appendix C.

\section{Conclusions}

Across a few dozen countries and nearly a decade and a half, we find that both global and local factors explain shipments of U.S. dollars abroad. In the aggregate, where only global factors appear to be relevant, we find that net shipments of dollars from the United States to other countries are very strongly correlated with measures of financial and economic uncertainty in the period since 2008 and considerably less so in earlier years. These correlations reflect a persistent, rather than episodic, relationship between currency flows and their determinants, such as uncertainty. Two interpretations appear to be consistent with this finding. First, U.S. dollars, as a safe asset, may provide hedging benefits on average rather just in times of stress. Second, times of stress in emerging market economies may be long-lasting, leading to persistent demand for U.S. dollars. Indeed, in contrast to VIX, news-based uncertainty measures are very persistent, likely reflecting long crisis spells.

For various country groupings, we evaluate the ability of both local and global factors to explain currency flows. We show that, since the global financial crisis, global economic

\footnotetext{
${ }^{36}$ On the operational side, the Federal Reserve is responsible for overseeing or implementing a wide array of tasks related to the production, distribution, use, and destruction of Federal Reserve notes. The Federal Reserve works with the Treasury's Bureau of Engraving and Printing to determine banknote design and production schedules. The Federal Reserve is then responsible for the storage, distribution, processing, and destruction of currency at its offices. The Federal Reserve also determines policies for banknote handling by commercial banks and, in cooperation with the Treasury, provides public education as necessary. Finally, the Federal Reserve works with the Treasury and the United States Secret Service to monitor and reduce counterfeiting.
} 
uncertainty has had an increasingly important role in explaining dollar flows, particularly to emerging market economies. The results also suggest a greater sensitivity of demand from abroad for U.S. banknotes to changes in economic uncertainty relative to changes in financial market stress. While currency flows to currency hubs (advanced countries that do not use U.S. banknotes but supply them to other countries and regions) also tend to respond to global economic uncertainty, those to advanced economies do not. These findings support the narrative that U.S. banknotes are used as a safe asset in emerging market economies. In addition, we show that local factors, such as inflation, also play a role in explaining currency flows. Similarly, when we group countries based on their flow patterns rather than their economic development, country-specific characteristics still predict dollar flows. In contrast to money demand theory, demand for U.S. currency appears to be interest rate insensitive.

In the spirit of the capital flows literature, we examine the ability of local and global factors to explain both low- and high-frequency components of currency flows. We find that the relationship between global uncertainty and U.S. dollar flows is persistent rather than episodic.

Our analysis has important implications for policy makers. From the perspective of foreign central banks, particularly those in emerging market economies, understanding and quantifying factors affecting demand for U.S. banknotes as a safe asset is crucial for their operations, including determining a desired size of foreign exchange reserves. In this context, one novel findings is the increased importance of global factors as determinants of currency flows for a given country. From the domestic perspective, understanding the factors driving international dollar flows - a major component of currency growth - is important for a wide range of Federal Reserve operational considerations and for the normalization of monetary policy.

Going forward, we envisage studying the implications of demand for U.S. banknotes from abroad on the Federal Reserve's operations and, hence, U.S. financial market functioning in more detail. In addition, for emerging market economies, we intend to explore the construction of risk or uncertainty indexes using our cross-border currency flow data and other country- or region-specific variables 37

\section{References}

Baker, S. R., N. Bloom, and S. J. Davis (2015): "Measuring economic policy uncertainty," mimeo.

\footnotetext{
${ }^{37}$ We can use the data as a measure of demand that relates to risk factors. For example, we can run a push-pull model of broader capital flows (other than currency flows), with currency flows as an explanatory factor that captures local risk. This approach may capture local factors that are, otherwise, very hard to proxy.
} 
Bartzsch, N., G. Rosl, And F. Seitz (2013): "Currency movements within and outside a currency union: The case of Germany and the euro area," The Quarterly Review of Economics and Finance, 53(4), 393-401.

Blanchard, O., M. Das, and H. Faruqee (2010): "The initial impact of the crisis on emerging market countries," Brookings Papers on Economic Activity, Spring, 263-307.

Board of Governors of the Federal Reserve System (2006): Purposes and functions. Washington, DC.

Calvo, G. A., L. Leiderman, and C. M. Reinhart (1993): "Capital inflows and real exchange rate appreciation in Latin America: The role of external factors," International Monetary Fund Staff Papers, 40(1), 108-151.

Chinn, M. D., And H. Ito (2006): "What matters for financial development? Capital controls, institutions, and interactions," Journal of Development Economics, 81(1), 163192.

Christiano, L. J., And T. J. Fitzgerald (2003): "The band pass filter," International Economic Review, 44(2), 435-465.

Chuhan, P., S. Claessens, and N. Mamingi (1998): "Equity and bond flows to Latin America and Asia: The role of global and country factors," Journal of Development Economics, 55(2), 439-463.

Clatessens, S., and K. Forbes (2004): "International financial contagion: The theory, evidence and policy implications," mimeo.

Doyle, B. (2000): "'Here, dollars, dollars...'- estimating currency demand and worldwide currency substitution," International Finance Discussion Paper, 657.

Fernandez-Arias, E. (1996): "The new wave of private capital inflows: Push or pull?," Journal of Development Economics, 48(2), 389-418.

Fischer, B., P. Kohler, and F. Seitz (2004): "The Demand for euro area currencies: Past, present, and future," European Central Bank Working Paper, 330.

Forbes, K. (2004): "The Asian flu and Russian virus: The international transmission of crises in firm-level data," Journal of International Economics, 63(1), 59-92.

Forbes, K. J., And F. E. WArnock (2012): "Capital flow waves: Surges, stops, flight, and retrenchment," Journal of International Economics, 88(2), 235-251.

Fratzscher, M. (2012): "Capital flows, push versus pull factors and the global financial crisis," Journal of International Economics, 88(2), 341 - 356.

Ghosh, A. R., M. S. Qureshi, J. I. Kim, and J. Zalduendo (2014): "Surges," Journal of International Economics, 92(2), 266 - 285.

Gourio, F., M. Siemer, and A. Verdelhan (2014): "Uncertainty and international capital flows," mimeo. 
Greenlaw, D., J. D. Hamilton, P. Hooper, and F. S. Mishkin (2013): "Crunch time: Fiscal crises and the role of monetary policy," NBER Working Paper, No. 19297.

Griffin, J., F. Nardari, and R. Stulz (2004): "Daily cross-border flows: Pushed or pulled?," Review of Economics and Statistics, 86(3), 641-657.

Hausman, J. A., And W. E. Taylor (1981): "Panel data and unobservable individual effects," Econometrica, 49(6), 1377-1398.

Hellerstein, R., And W. Ryan (2011): "Cash dollars abroad," Federal Reserve Bank of New York Reports, (400).

Judson, R. A. (2012): "Crisis and calm: Demand for U.S. currency at home and abroad from the fall of the Berlin Wall to 2011," Federal Reserve International Finance Discussion Paper, 1058.

Judson, R. A., And R. D. Porter (1996): "The location of U.S. currency: How much is abroad?," Federal Reserve Bulletin, 82, 883-903.

KAmin, S. B., And N. R. ERICSSON (2003): "Dollarization in post-hyperinflationary Argentina," Journal of International Money and Finance, 22(2), 185 - 211.

Stix, H. (2010): "Euroization: What factors drive its persistence? Household data evidence for Croatia, Slovenia, and Slovakia," Applied Economics, 32(21), 2689-2704.

U.S. Census Bureau (2012): Statistical Abstract of the United States. Washington, DC.

U.S. Department of the Treasury (2006): The use and counterfeiting of U.S. currency abroad, part III. Washington, DC. 


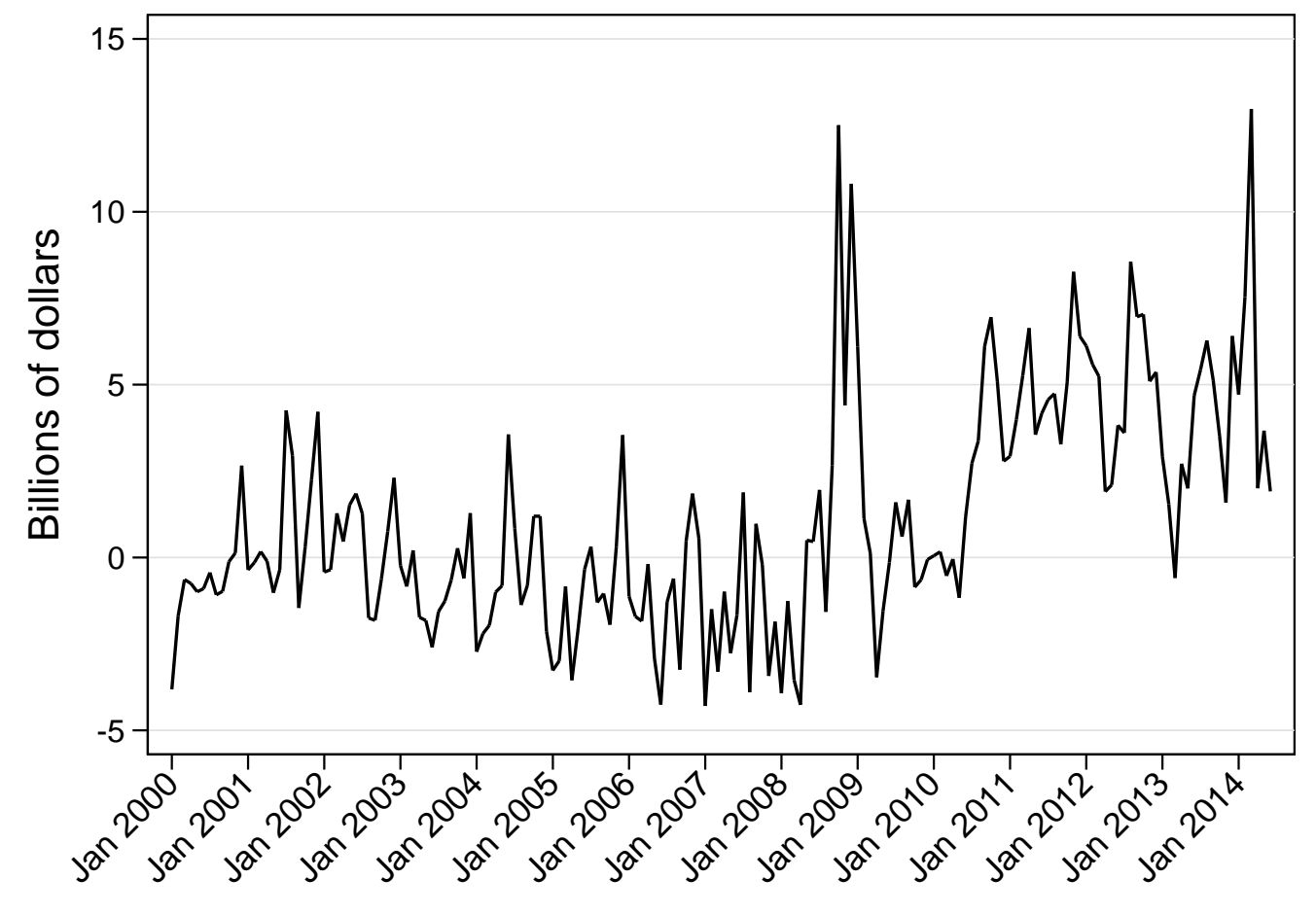

Figure 1: Monthly net shipments of U.S. dollars, in aggregate 


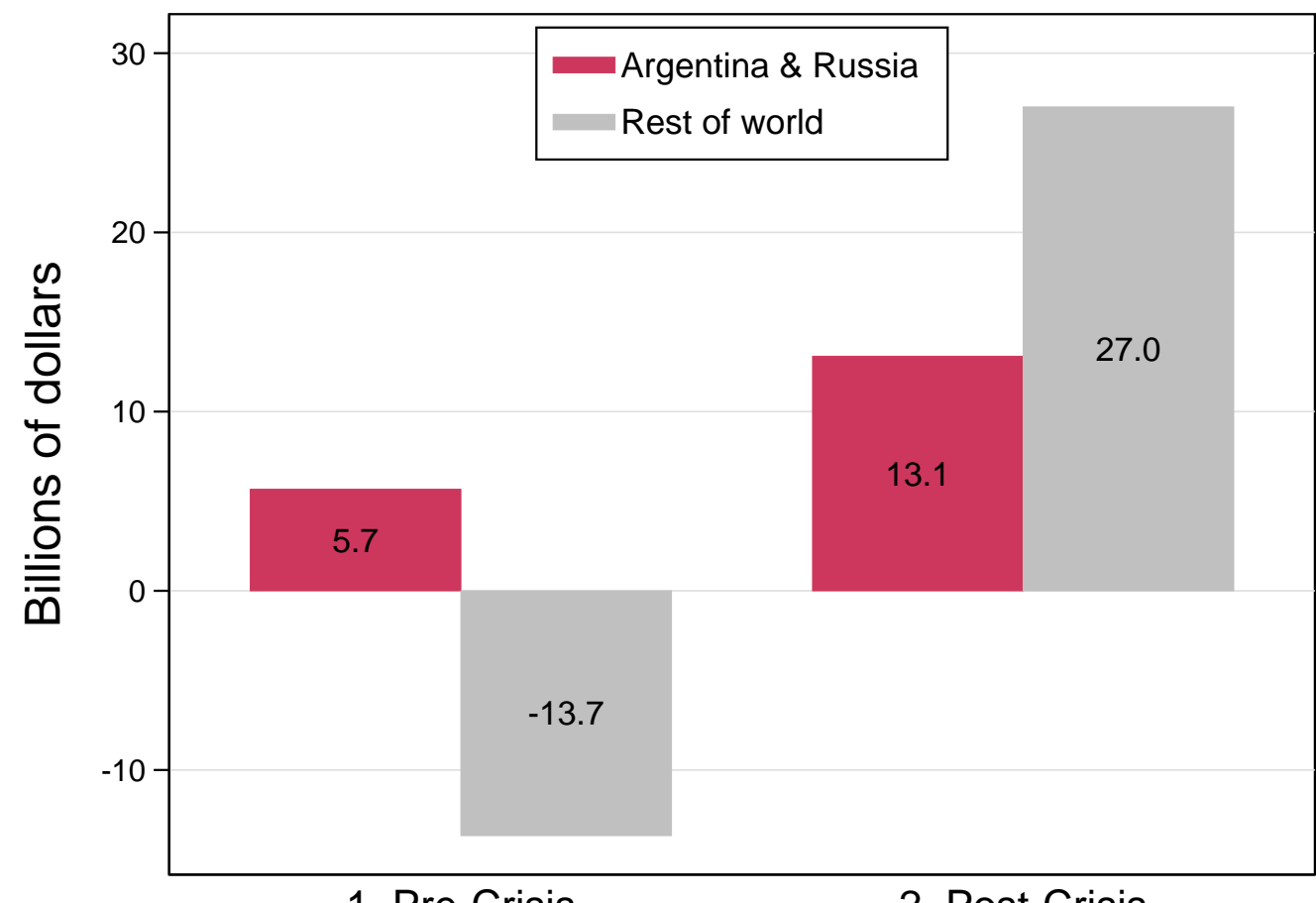

1. Pre-Crisis

2. Post-Crisis

Figure 2: Average annual net payments for Argentina, Russia, and rest of the world 


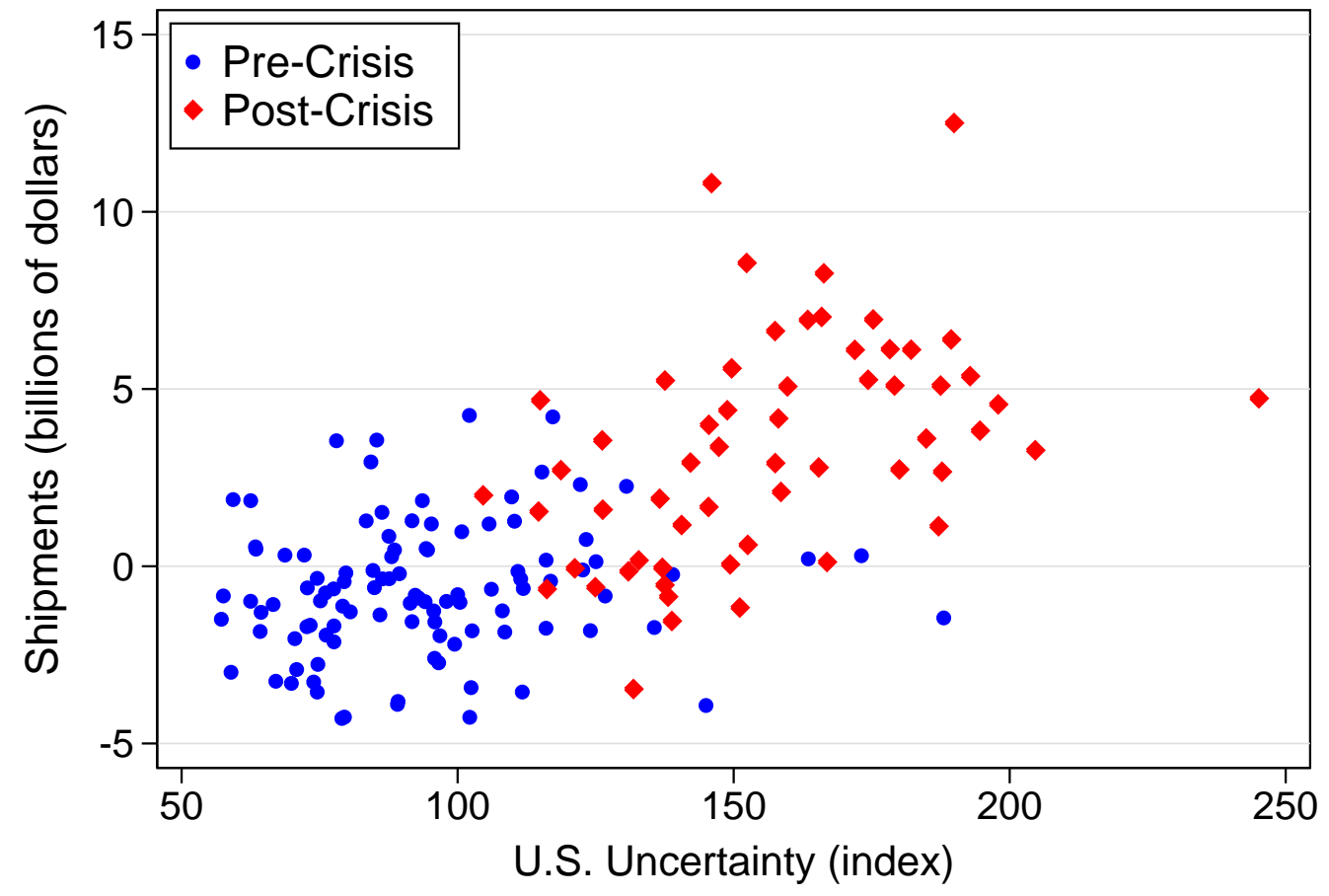

Source. Federal Reserve; Baker, Bloom, and Davis.

Figure 3: Uncertainty index and net currency shipments 

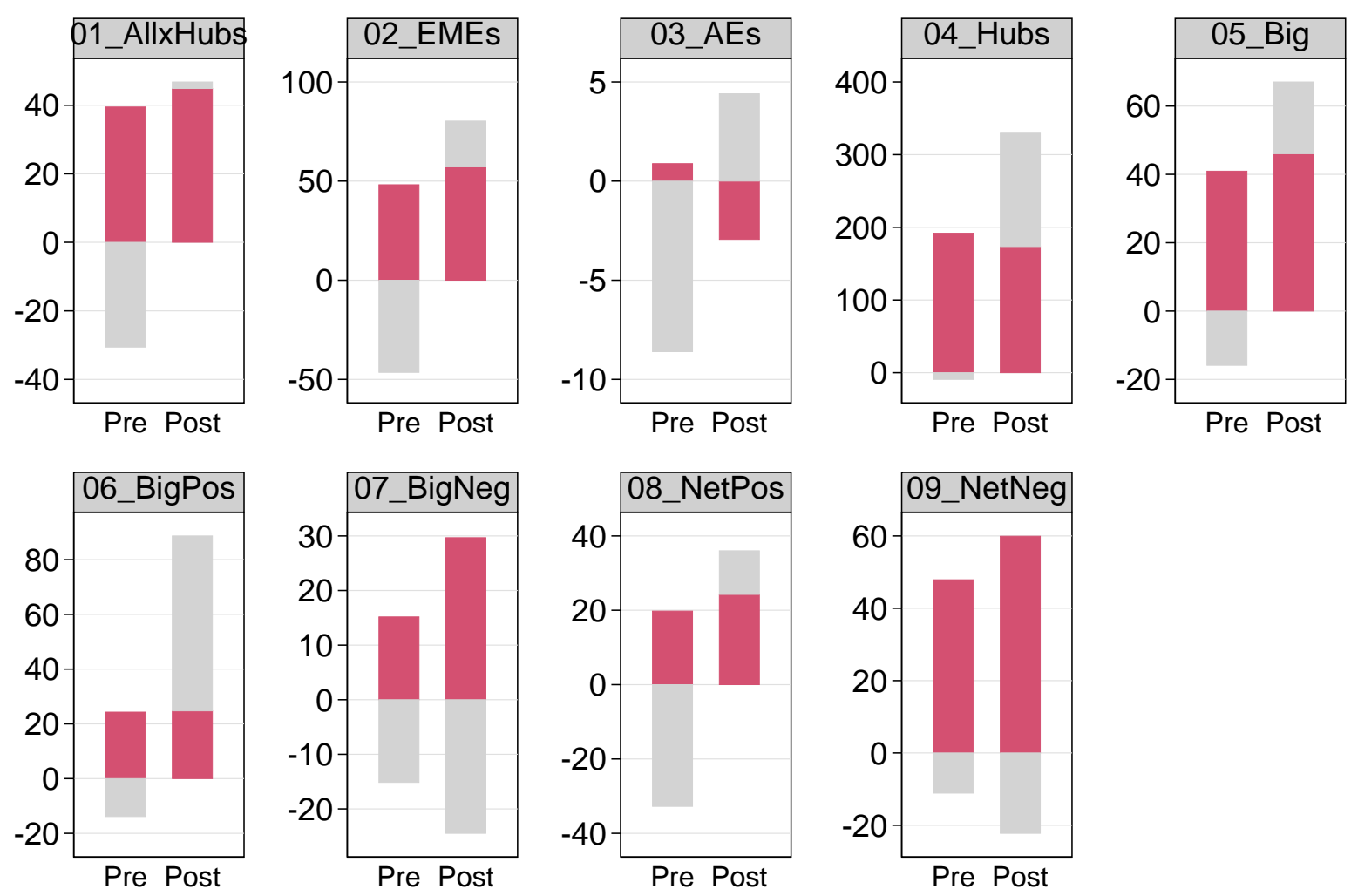

Local Global

Figure 4: Factor contributions to net currency shipments for all countries, including hubs (basis points of GDP in U.S. dollars) 


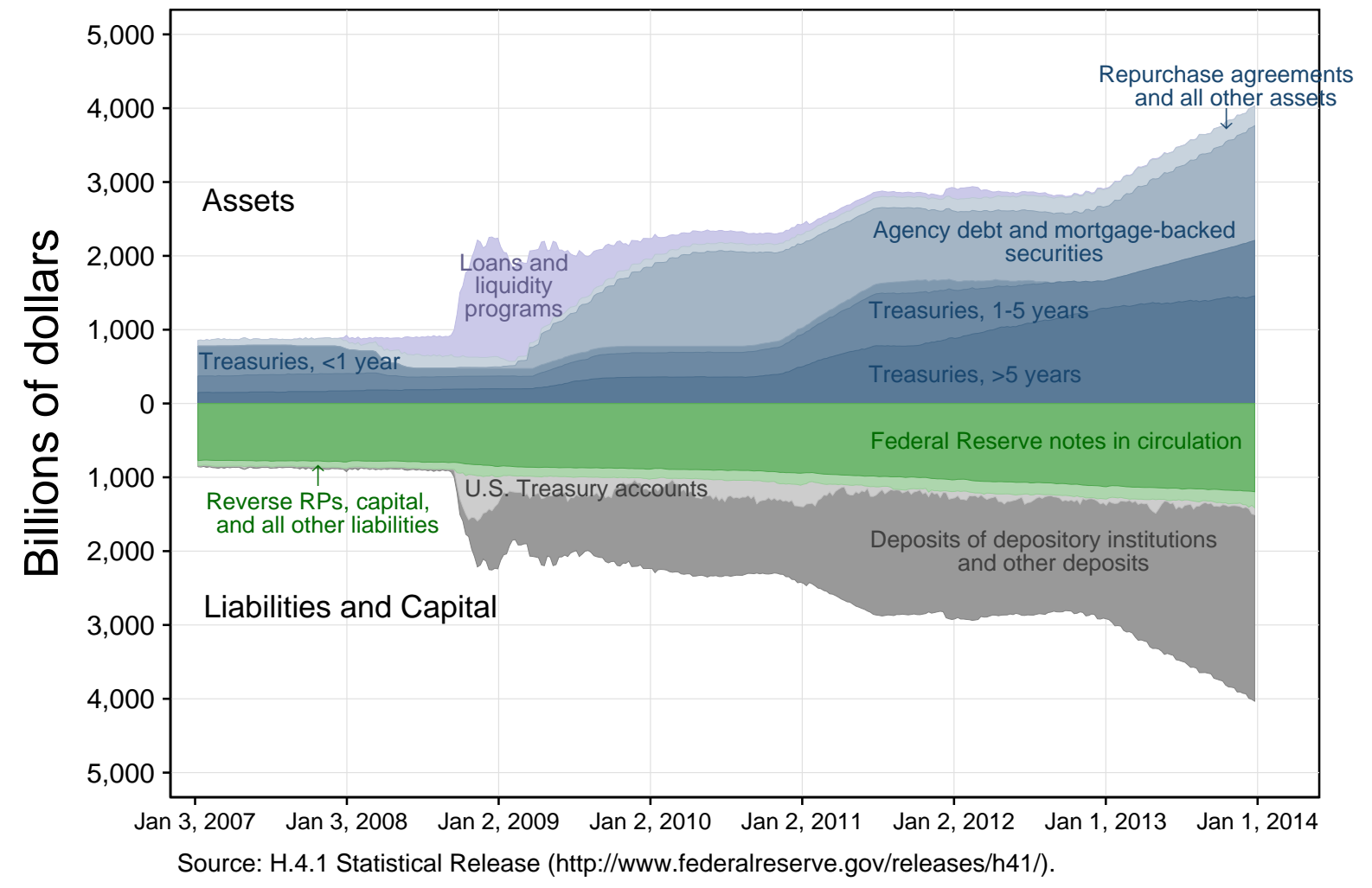

Figure 5: Federal Reserve assets and liabilities, 2007-2014

Table 1: Monthly net shipments in aggregate, millions of U.S. dollars

\begin{tabular}{lrrrrrr}
\hline \hline & Number of & \multicolumn{5}{c}{ Net shipments } \\
& observations & Mean & Stand.dev. & Median & 5th pct & 95th pct \\
\hline Full sample & 162 & 777 & 3,079 & 4 & $-3,463$ & 6,398 \\
Pre-crisis & 104 & -666 & 1,869 & -810 & $-3,814$ & 2,658 \\
Crisis & 58 & 3,364 & 3,140 & 3,322 & $-1,165$ & 8,557 \\
\hline \hline
\end{tabular}


Table 2: Aggregate regressions

\begin{tabular}{lcccc}
\hline \hline & EMBI+VIX & Uncert. only & Uncert. PCAs & Add'l Vars. \\
\hline EMBI (Total) & $-2.8^{*}$ & & & \\
VIX & $134.7^{* *}$ & & & \\
US policy uncert. & & $32.0^{* *}$ & & \\
EU policy uncert. & & $21.0^{+}$ & & \\
Uncert. and stress & & $919.0^{* *}$ & $803.2^{* *}$ \\
Uncert. vs stress & & $1086.4^{* *}$ & $1126.9^{* *}$ \\
U.S. vs Europe & & $1229.3^{* *}$ & $1115.9^{*}$ \\
Global GDP growth & & & -110.1 \\
Global inflation & & & 309.4 \\
Broad dollar apprec. & & & & -72.4 \\
Oil price growth & & & & -38.5 \\
Gold price growth & & & & 54.7 \\
Constant & -922.0 & $-5312.7^{* *}$ & $797.5^{* *}$ & -36.2 \\
\hline Num. of observations & 162 & 162 & 162 & 162 \\
Adjusted R ${ }^{2}$ & 0.09 & 0.40 & 0.39 & 0.39 \\
\hline
\end{tabular}

Note. Dependent variable: NSA monthly total net shipments in millions of dollars.

Sept.-Oct. 2008 included. ${ }^{+} p<0.10,{ }^{*} p<0.05,{ }^{* *} p<0.01$.

Table 3: Principal components factor loadings

\begin{tabular}{lccc}
\hline \hline Data input & $\begin{array}{c}\text { Market stress and } \\
\text { policy uncertainty }\end{array}$ & $\begin{array}{c}\text { Policy uncertainty } \\
\text { vs. market stress }\end{array}$ & $\begin{array}{c}\text { U.S. vs. European } \\
\text { stress / uncertainty }\end{array}$ \\
\hline VIX & 0.50 & -0.52 & 0.20 \\
VSTOXX & 0.52 & -0.44 & -0.34 \\
U.S. uncertainty & 0.51 & 0.44 & 0.70 \\
European uncertainty & 0.47 & 0.58 & -0.60 \\
\hline Portion of variance explained & 0.70 & 0.24 & 0.05 \\
\hline \hline
\end{tabular}


Table 4: Aggregate regressions with separate pre- and post-crisis coefficients

\begin{tabular}{|c|c|c|c|}
\hline & Full sample & PCAs & PCAs+Macro \\
\hline Uncert. and stress & $803.2^{* *}$ & & \\
\hline Uncert. and stress, pre-crisis & & 194.9 & -107.4 \\
\hline Uncert. and stress, post-crisis & & $1246.3^{* *}$ & $775.6^{*}$ \\
\hline Uncert. vs stress & $1126.9^{* *}$ & & \\
\hline Uncert. vs stress, pre-crisis & & 95.6 & -179.5 \\
\hline Uncert. vs stress, post-crisis & & $1012.6^{*}$ & $754.3^{*}$ \\
\hline U.S. vs Europe & $1115.9^{*}$ & & \\
\hline U.S. vs Europe, pre-crisis & & 122.1 & 493.4 \\
\hline U.S. vs Europe, post-crisis & & 352.1 & 122.4 \\
\hline Global GDP growth & -110.1 & & \\
\hline Global GDP growth, pre-crisis & & & $-652.7^{* *}$ \\
\hline Global GDP growth, post-crisis & & & -206.5 \\
\hline Global inflation & 309.4 & & \\
\hline Global inflation, pre-crisis & & & -280.0 \\
\hline Global inflation, post-crisis & & & $1460.3^{* *}$ \\
\hline Broad dollar apprec. & -72.4 & & \\
\hline Broad dollar apprec., pre-crisis & & & -289.7 \\
\hline Broad dollar apprec., post-crisis & & & -713.8 \\
\hline Gold price growth & 54.7 & & \\
\hline Gold price growth, pre-crisis & & & 52.6 \\
\hline Gold price growth, post-crisis & & & 40.7 \\
\hline Oil price growth & -38.5 & & \\
\hline Oil price growth, pre-crisis & & & -15.1 \\
\hline Oil price growth, post-crisis & & & $-104.0^{+}$ \\
\hline Post-crisis (dummy) & & $1592.1^{*}$ & $-5781.4^{* *}$ \\
\hline Constant & -36.2 & -483.2 & $2778.2^{+}$ \\
\hline Num. of observations & 162 & 162 & 162 \\
\hline Adjusted $\mathrm{R}^{2}$ & 0.39 & 0.47 & 0.55 \\
\hline
\end{tabular}

Note. Dependent variable: NSA monthly total net shipments in millions of dollars.

${ }^{+} p<0.10,{ }^{*} p<0.05,{ }^{* *} p<0.01$. 
Table 5: Country groupings

\begin{tabular}{|c|c|}
\hline Groups & Included countries (codes) \\
\hline \multicolumn{2}{|c|}{ By levels of economic development } \\
\hline Emerging market economies & $\begin{array}{l}\text { ARG BRA CHL CHN CZE EGY EST HUN KAZ MEX } \\
\text { PHL POL RUS SVN THA TUR UKR }\end{array}$ \\
\hline Advanced economies & $\begin{array}{l}\text { AUS BEL CAN DNK ESP FIN FRA GRC IRL ISL } \\
\text { ITA JPN KOR LUX NLD NOR NZL PRT SWE }\end{array}$ \\
\hline Currency hubs & AUT CHE DEU GRB HKG SGP \\
\hline \multicolumn{2}{|c|}{ By patterns of currency flows } \\
\hline "Big" & $\begin{array}{l}\text { BRA CAN CHL CHN EGY JPN KAZ KOR MEX PHL } \\
\text { RUS THA TUR UKR }\end{array}$ \\
\hline "BigPos" & BRA CAN JPN KAZ KOR RUS UKR \\
\hline "BigNeg" & CHL CHN EGY MEX PHL THA TUR \\
\hline "NetPos" & $\begin{array}{l}\text { ARG AUS BEL BRA CAN CZE DNK ESP EST FIN } \\
\text { FRA GRC HUN IRL ISR ITA JPN KAZ KOR LUX } \\
\text { NLD NOR NZL RUS SVN SWE UKR }\end{array}$ \\
\hline "NetNeg" & CHL CHN EGY MEX PHL POL PRT THA TUR \\
\hline
\end{tabular}

Table 6: Net shipment/GDP by levels of development, basis points

\begin{tabular}{lrrrrrr}
\hline \hline \multicolumn{1}{c}{ Period } & Num. of obs. & Mean & Stand.dev. & Median & 5th pct & 95th pct \\
\hline All countries excluding hubs & & & & & \\
Full sample & 5,696 & 6 & 85 & 1 & -100 & 124 \\
$\begin{array}{l}\text { Pre-crisis } \\
\text { Crisis }\end{array}$ & 3,626 & 4 & 86 & 1 & -111 & 108 \\
$\begin{array}{l}\text { Emerging market } \\
\text { Full sample }\end{array}$ & 2,070 & 10 & 82 & 0 & -82 & 174 \\
$\begin{array}{l}\text { Pre-crisis } \\
\text { Crisis }\end{array}$ & 2,672 & 7 & 122 & 0 & -136 & 240 \\
$\begin{array}{l}\text { Advanced economies } \\
\text { Full sample }\end{array}$ & 1,702 & 2 & 124 & -1 & -143 & 220 \\
$\begin{array}{l}\text { Pre-crisis } \\
\text { Crisis }\end{array}$ & 970 & 17 & 119 & 0 & -110 & 279 \\
Currency hubs & 1,024 & 5 & 18 & 1 & -13 & 34 \\
Full sample & 1,924 & 6 & 21 & 2 & -12 & 37 \\
$\begin{array}{l}\text { Pre-crisis } \\
\text { Crisis }\end{array}$ & 1,100 & 3 & 13 & 1 & -18 & 25 \\
\hline \hline
\end{tabular}

Note. The ratio is defined as annualized monthly net shipments over annual GDP, both in U.S. dollars. 
Table 7: Net shipment/GDP by patterns of flows, basis points

\begin{tabular}{crrrrrr}
\hline \hline Period & Num. of obs. & Mean & Stand.dev. & Median & 5th pct & 95th pct \\
\hline "Big" & & & & & & \\
Full sample & 2,238 & 0 & 110 & -3 & -142 & 232 \\
Pre-crisis & 1,441 & -6 & 108 & -5 & -146 & 213 \\
Crisis & 797 & 10 & 113 & -1 & -119 & 266 \\
"BigPos" & & & & & & \\
Full sample & 1,119 & 62 & 115 & 15 & -23 & 322 \\
Pre-crisis & 715 & 56 & 111 & 11 & -25 & 302 \\
Crisis & 404 & 73 & 120 & 18 & -18 & 335 \\
"BigNeg" & & & & & & \\
Full sample & 1,119 & -63 & 57 & -50 & -164 & 0 \\
Pre-crisis & 726 & -67 & 59 & -59 & -172 & 0 \\
Crisis & 393 & -55 & 53 & -43 & -158 & 0 \\
"NetPos" & & & & & & \\
Full sample & 4,265 & 26 & 84 & 2 & -7 & 178 \\
Pre-crisis & 2,704 & 25 & 85 & 3 & -9 & 145 \\
Crisis & 1,561 & 27 & 82 & 1 & -2 & 216 \\
"NetNeg" & & & & & & \\
Full sample & 1,431 & -51 & 55 & -31 & -157 & 1 \\
Pre-crisis & 922 & -54 & 58 & -32 & -159 & 1 \\
Crisis & 509 & -45 & 51 & -30 & -147 & 0 \\
\hline \hline
\end{tabular}

Note. The ratio is defined as annualized monthly net shipments over annual GDP, both in U.S. dollars.

Table 8: Panel regressions by levels of development

\begin{tabular}{lcccc}
\hline \hline & AllxHubs & EMEs & AEs & Hubs \\
\hline Equity mkt vol, pre-crisis & $3.0^{* *}$ & $3.9^{* *}$ & -0.1 & -0.2 \\
Equity mkt vol, crisis & $1.4^{* *}$ & $1.6^{*}$ & $0.7^{* *}$ & -1.9 \\
Inflation, pre-crisis & $1.2^{* *}$ & $1.2^{* *}$ & $0.9^{* *}$ & $-11.2^{* *}$ \\
Inflation, crisis & $3.5^{* *}$ & $3.2^{* *}$ & $-1.9^{* *}$ & $-12.8^{* *}$ \\
FX res. growth, pre-crisis & $-1.3^{* *}$ & $-3.5^{* *}$ & -0.1 & $1.9^{+}$ \\
FX res. growth, crisis & -0.1 & -0.7 & -0.0 & 0.4 \\
Uncert. and stress, crisis & $2.8^{*}$ & $8.7^{* *}$ & $-1.3^{*}$ & $14.5^{* *}$ \\
Uncert. vs stress, pre-crisis & -1.2 & -1.0 & -0.9 & $28.8^{* *}$ \\
Uncert. vs stress, crisis & $3.9^{* *}$ & $6.5^{*}$ & 0.8 & $12.1^{*}$ \\
U.S. vs Europe, crisis & 0.7 & 2.4 & 0.6 & $28.2^{* *}$ \\
Cumulative ship/GDP & $9.3^{* *}$ & $9.4^{* *}$ & 5.0 & $14.0^{* *}$ \\
\hline Num. of observations & 5696 & 2672 & 3024 & 971 \\
Num. of countries & 36 & 17 & 19 & 6 \\
$\mathrm{R}^{2}$ & 0.56 & 0.57 & 0.28 & 0.67 \\
\hline \hline
\end{tabular}

Note. Dependent variable: Net shipments/GDP. Sept. 2008 and Oct. 2008 included. EMEs includes Argentina, Eastern Europe, and FSU. Endogenous variables are FX reserves growth and cumulative shipments. Not all control variables shown. ${ }^{+} p<0.10,{ }^{*} p<0.05,{ }^{* *} p<0.01$. 
Table 9: Panel regressions by patterns of flows

\begin{tabular}{lcccccc}
\hline \hline & AllxHubs & Big & BigPos & BigNeg & NetPos & NetNeg \\
\hline Equity mkt vol, pre-crisis & $3.0^{* *}$ & $1.8^{* *}$ & $1.4^{*}$ & $2.2^{* *}$ & $3.1^{* *}$ & $2.1^{* *}$ \\
Equity mkt vol, crisis & $1.4^{* *}$ & -0.0 & $-1.7^{+}$ & $1.7^{* *}$ & $1.1^{*}$ & $1.5^{* *}$ \\
Inflation, pre-crisis & $1.2^{* *}$ & $2.0^{* *}$ & $1.7^{* *}$ & $2.0^{* *}$ & 0.2 & $1.9^{* *}$ \\
Inflation, crisis & $3.5^{* *}$ & $3.9^{* *}$ & $3.0^{* *}$ & $5.6^{* *}$ & $2.4^{* *}$ & $5.5^{* *}$ \\
FX res. growth, pre-crisis & $-1.3^{* *}$ & $-3.0^{* *}$ & $-3.5^{* *}$ & $-1.9^{* *}$ & $-1.4^{* *}$ & $-0.9^{* *}$ \\
FX res. growth, crisis & -0.1 & $-2.8^{* *}$ & $-3.6^{* *}$ & 0.1 & -0.1 & -0.1 \\
Uncert. and stress, crisis & $2.8^{*}$ & $6.4^{* *}$ & $11.2^{* *}$ & 1.4 & $3.8^{*}$ & 0.3 \\
Uncert. vs stress, pre-crisis & -1.2 & 1.9 & 2.6 & 0.5 & -2.0 & 0.4 \\
Uncert. vs stress, crisis & $3.9^{* *}$ & $6.7^{* *}$ & 4.2 & $6.5^{* *}$ & $3.1^{+}$ & $4.9^{* *}$ \\
U.S. vs Europe, crisis & 0.7 & $7.9^{+}$ & 11.0 & 4.6 & 0.1 & 3.9 \\
Cumulative ship/GDP & $9.3^{* *}$ & $8.9^{* *}$ & $6.2^{+}$ & -4.0 & $8.0^{* *}$ & -0.7 \\
\hline Num. of observations & 5696 & 2238 & 1119 & 1119 & 4265 & 1431 \\
Num. of countries & 36 & 14 & 7 & 7 & 27 & 9 \\
$\mathrm{R}^{2}$ & 0.56 & 0.71 & 0.62 & 0.49 & 0.47 & 0.56 \\
\hline \hline
\end{tabular}

Note. Dependent variable: Net shipments/GDP. Sept. 2008 and Oct. 2008 included. Hubs excluded from all groups. Endogenous variables are FX reserves growth and cumulative shipments. Not all control variables shown. ${ }^{+} p<0.10,{ }^{*} p<0.05,{ }^{* *} p<0.01$.

Table 10: Panel regressions by levels of development at a low frequency

\begin{tabular}{lcccc}
\hline \hline & AllxHubs & EMEs & AEs & Hubs \\
\hline Equity mkt vol, pre-crisis & $2.3^{* *}$ & $3.1^{* *}$ & -0.1 & 1.4 \\
Equity mkt vol, crisis & $1.3^{* *}$ & $1.7^{* *}$ & $0.5^{* *}$ & -1.6 \\
Inflation, pre-crisis & $1.2^{* *}$ & $1.2^{* *}$ & $0.9^{* *}$ & $-11.6^{* *}$ \\
Inflation, crisis & $3.5^{* *}$ & $3.2^{* *}$ & $-1.9^{* *}$ & $-14.4^{* *}$ \\
FX res. growth, pre-crisis & $-0.4^{* *}$ & $-1.0^{* *}$ & -0.0 & 1.3 \\
FX res. growth, crisis & -0.1 & -0.4 & -0.0 & 0.4 \\
Uncert. and stress, crisis & $1.6^{+}$ & $5.8^{* *}$ & $-1.0^{*}$ & $14.6^{* *}$ \\
Uncert. vs stress, pre-crisis & -0.3 & -0.1 & $-1.1^{+}$ & $30.7^{* *}$ \\
Uncert. vs stress, crisis & $3.0^{* *}$ & $4.6^{*}$ & $0.9^{+}$ & $13.4^{* *}$ \\
U.S. vs Europe, crisis & -0.2 & 0.1 & 0.7 & 11.8 \\
Cumulative ship/GDP & $9.3^{* *}$ & $9.4^{* *}$ & 4.8 & $14.0^{* *}$ \\
\hline Num. of observations & 5696 & 2672 & 3024 & 971 \\
Num. of countries & 36 & 17 & 19 & 6 \\
$\mathrm{R}^{2}$ & 0.72 & 0.74 & 0.35 & 0.78 \\
\hline \hline
\end{tabular}

Note. Dependent variable: Low-frequency component of net shipments/GDP.

Sept. 2008 and Oct. 2008 included. EME includes Argentina, Eastern Europe, and FSU. Endogenous variables are FX reserves growth and cumulative shipments.

Not all control variables shown. ${ }^{+} p<0.10,{ }^{*} p<0.05,{ }^{* *} p<0.01$. 
Table 11: Panel regressions by patterns of flows at a low frequency

\begin{tabular}{lcccccc}
\hline \hline & AllxHubs & Big & BigPos & BigNeg & NetPos & NetNeg \\
\hline Equity mkt vol, pre-crisis & $2.3^{* *}$ & $1.4^{* *}$ & $1.1^{*}$ & $1.6^{* *}$ & $2.5^{* *}$ & $1.5^{* *}$ \\
Equity mkt vol, crisis & $1.3^{* *}$ & $1.1^{*}$ & 0.3 & $1.4^{* *}$ & $0.9^{*}$ & $1.7^{* *}$ \\
Inflation, pre-crisis & $1.2^{* *}$ & $2.0^{* *}$ & $1.6^{* *}$ & $2.0^{* *}$ & 0.3 & $1.6^{* *}$ \\
Inflation, crisis & $3.5^{* *}$ & $3.8^{* *}$ & $2.9^{* *}$ & $5.7^{* *}$ & $1.5^{* *}$ & $6.5^{* *}$ \\
FX res. growth, pre-crisis & $-0.4^{* *}$ & $-1.0^{* *}$ & $-1.0^{*}$ & $-1.1^{* *}$ & $-0.3^{*}$ & $-0.7^{*}$ \\
FX res. growth, crisis & -0.1 & $-1.8^{* *}$ & $-2.0^{* *}$ & -0.7 & -0.0 & -0.1 \\
Uncert. and stress, crisis & $1.6^{+}$ & $3.4^{*}$ & $6.6^{*}$ & 0.1 & $3.6^{* *}$ & 1.8 \\
Uncert. vs stress, pre-crisis & -0.3 & -0.9 & 1.2 & -3.2 & $4.0^{*}$ & 1.9 \\
Uncert. vs stress, crisis & $3.0^{* *}$ & $6.0^{* *}$ & 4.0 & $6.8^{* *}$ & $3.3^{*}$ & $5.8^{* *}$ \\
U.S. vs Europe, crisis & -0.2 & -0.1 & -4.1 & 4.3 & 2.0 & 4.3 \\
Cumulative ship/GDP & $9.3^{* *}$ & $8.8^{* *}$ & $6.2^{+}$ & -4.0 & $7.9^{* *}$ & 11.9 \\
\hline Num. of observations & 5696 & 2238 & 1119 & 1119 & 4912 & 1755 \\
Num. of countries & 36 & 14 & 7 & 7 & 31 & 11 \\
R & 0.72 & 0.81 & 0.75 & 0.58 & 0.59 & 0.80 \\
\hline \hline
\end{tabular}

Note. Dependent variable: Low-frequency component of net shipments/GDP. Sept. 2008 and Oct. 2008 included. Hubs excluded from all groups. Endogenous variables are FX reserves growth and cumulative shipments. Not all control variables shown. ${ }^{+} p<0.10,{ }^{*} p<0.05,{ }^{* *} p<0.01$. 


\section{Appendix A. Currency data sources and definitions}

Several agencies and publications carry data on U.S. currency in circulation, and several additional sources are available internally in the Federal Reserve. The publications and the level of detail provided by each source are summarized in the table. None of these sources provides any information about domestic and international movements of U.S. currency.

In principle, the most obvious direct source of information on U.S. currency flows across U.S. borders should be the Currency and Monetary Instrument Reports (CMIRs), which are compiled by the U.S. Customs Service. Individuals and firms making almost any shipment of more than $\$ 10,000$ in cash across a U.S. border are required to file CMIRs, so these reports should be quite comprehensive and informative. However, as noted in U.S. Department of the Treasury (2006), CMIRs are neither accurate nor thorough measures of large cash shipments outside the banking sector due to three shortcomings.

First, all individuals entering or leaving the United States are required to complete a CMIR if they are carrying more than $\$ 10,000$ in currency or monetary instruments. In practice, though, customs formalities, including a specific question about currency and monetary instruments, are required for individuals entering the United States, but not for individuals exiting the United States ${ }^{38}$ As a result, it seems plausible that underreporting is more likely for outbound travelers.

Second, even if all travelers were to report accurately, the CMIRs require no reporting for sums below $\$ 10,000$; in aggregate, these sums could be considerable. In 2009, 151 million passengers arrived and departed on international flights at U.S. airports and about 200 million border crossings occurred by land in 2009 (see U.S. Census Bureau (2012)). The net movements of currency across U.S. borders through such nonbank channels are potentially significant. Indeed, as noted in U.S. Department of the Treasury (2006), customs reporting for Mexico indicates substantial cash flows from the United States to Mexico in the hands of tourists and migrants; such flows, since they typically occur in amounts of less than $\$ 10,000$ and through nonbank channels, are not captured in U.S. data.

Third, the CMIRs do not account properly for shipments to international custodial holding sites for the U.S. currency. These sites, known as Extended Custodial Inventories, or ECIs, are secure locations outside the United States at which U.S. currency is held in custody for the Federal Reserve Bank of New York. Shipments to these sites are recorded in U.S. Customs data when they physically exit the United States, even though they remain in the custody of the Federal Reserve Bank of New York. Thus, for example, a shipment to an ECI in Switzerland will be recorded as a shipment to Switzerland on the day it occurs even though the currency is not in circulation 39

\footnotetext{
${ }^{38}$ Passengers on flights departing the United States are sometimes questioned or informed about this reporting requirement, but coverage is far from complete.

${ }^{39}$ Refer to U.S. Department of the Treasury (2006), Chapter 5, for more details about ECIs.
} 
In addition to these three shortcomings for the CMIR data coverage of overall flows, the CMIR data country attribution is problematic. CMIR reporting requires only information about the immediate source or destination of currency flows, not the ultimate source or destination like the commercial bank shipment data. For example, if an institution ships currency to Russia via Germany, the commercial bank shipment data from a reporting institution would record the destination as Russia while the CMIR data would report the destination as Germany. We therefore consider the Federal Reserve shipments data described above to be superior to the CMIR data, and hence we do not use the CMIR data in this study 40

\section{Appendix B. Principal components analysis}

Principal components analysis (PCA) is statistical technique used to transform the variance structure of a standardized set of correlated, observed variables into an identical number of linearly uncorrelated latent variables. We extracted principal components from four inputs: month-average values of the VIX and VSTOXX indices, and the monthly U.S. and European economic policy uncertainty indices discussed in the text ${ }^{41}$ These series were chosen as proxy measures of market stress and economic policy uncertainty in the U.S. and developed Europe. They have been highly correlated to one another since the beginning of 2000, although the two proxies for market stress have been less highly correlated to the two policy uncertainty indices than they were earlier since the 2008 financial crisis.

Principal component scores are computed by summing the products of factor loadings and standardized versions of the PCA inputs. A positive factor loading indicates positive correlation between principal component scores and an input, and a loading that is larger in magnitude indicates stronger correlation than a loading with a smaller magnitude. Table 3 lists the loadings produced by our PCA analysis. All loadings for the first principal component (market stress and policy uncertainty) are positive, and the variation of this principal component therefore captures variation that is common to all four inputs. Loadings for the second principal component (policy uncertainty vs. market stress) indicate that it tracks differences between co-movements of the economic policy uncertainty indices and comovements of the two market stress proxies based on variation that is not captured by the first principal component, and thus can be used to distinguish between the impact on currency

\footnotetext{
${ }^{40}$ For researchers who do not have access to the shipment data, or for certain countries and time periods, the CMIR data can provide useful insights. Refer, for example, Kamin and Ericsson (2003) for analysis of dollarization in Argentina. For the latter analysis, CMIR data were both available over a longer time period and more reliable than usual because of the patterns of dollar flows to Argentina.

${ }^{41}$ The VSTOXX index is similar to the VIX, but is calculated using European option prices rather than U.S. option prices. Specifically, it is derived from the implied volatility of 1-month options on the STOXX index of 50 large-cap European equities. In this analysis, we use the VIX as a proxy for market stress in the U.S. and the VSTOXX as a proxy for market stress in developed Europe.
} 
demand of changes in economic policy uncertainty relative to market stress. Analogously, the third factor (U.S. vs. European stress/uncertainty) distinguishes between the impact of changes in the U.S. relative to changes in Europe based on variation that is not captured by the first two principal components. Scores for the fourth principal component simply capture residual variance that is not captured by the first three.

\section{Appendix C: Implications of currency demand from abroad for reserves draining and normalization of monetary policy}

From the domestic perspective, understanding the factors driving international dollar usage has important implications for monetary policy normalization, including daily open market operations and potential large-scale liquidity draining operations, and the management of the Federal Reserve's portfolio, among others. In particular, the higher the currency growth, the more reserve balances get drained by this autonomous factor, and, hence, the less reserve balances should be drained by the Federal Reserve to normalize its balance sheet. In addition, in the process, the Federal Reserve will spend less on remuneration of reserve balances, and, hence, will remit more to the U.S. Treasury.

Currency growth decelerated from 8.6 percent in 2012 to 6.3 percent in 2013. This deceleration coincided with decreases in the average value of the European uncertainty index (from 186 in 2012 to 141 in 2013) and the U.S. uncertainty index decreased (from 168 to 122). Based on the empirical results presented in sections 5 and 6, currency growth may decelerate further over the next few years if uncertainty in Europe and the U.S. continues to abate.

The ongoing deceleration of currency growth has important implications for the exit strategy through which the FOMC will normalize the conduct of monetary policy over the next several years. The key elements of this strategy are monetary policy measures through which the Federal Reserve will normalize the size of its balance sheet and reduce reserves to the smallest levels that are consistent with the implementation of monetary policy. Currency growth drains reserves, and the rate at which currency grows therefore will be one of the parameters that determine the amount of time needed to complete the exit and the sizes of reserves-draining operations involved.

Greenlaw, Hamilton, Hooper, and Mishkin (2013) used the normalization principles articulated in the minutes of the FOMC's June 2011 meeting, along with assumptions about future interest rates and currency growth, to project the impact of the strategy's implementation on future reserves levels and remittances of earnings by the Federal Reserve to the Treasury. We use their assumptions to illustrate how slower currency growth would impact normalization outcomes.

To make their projections, Greenlaw, Hamilton, Hooper, and Mishkin (2013) assume 
currency will grow at an annual rate of 7 percent through 2020, by which time they expect normalization to be completed. Coincidentally, this is the average growth rate for 2008-2013, when U.S. and European policy uncertainty was elevated relative to what it was prior to the 2008 financial crisis. Currency grew at slower rates averaging annual rate of 4 percent during 2000-2007, when uncertainty in the U.S. and Europe was lower. Figure A1 illustrates these points. It shows cumulative net payments of currency (both domestic and international) over the course of the year for recent years. The red line, 2008, tracks the gray line, the average of 2003-2007, until mid-September, at which point it turns up sharply. Subsequent years show elevated patterns much more similar to the latter part of 2008 than to the years prior to 2008. Future currency growth rates might be closer to this average if uncertainty continues to diminish.

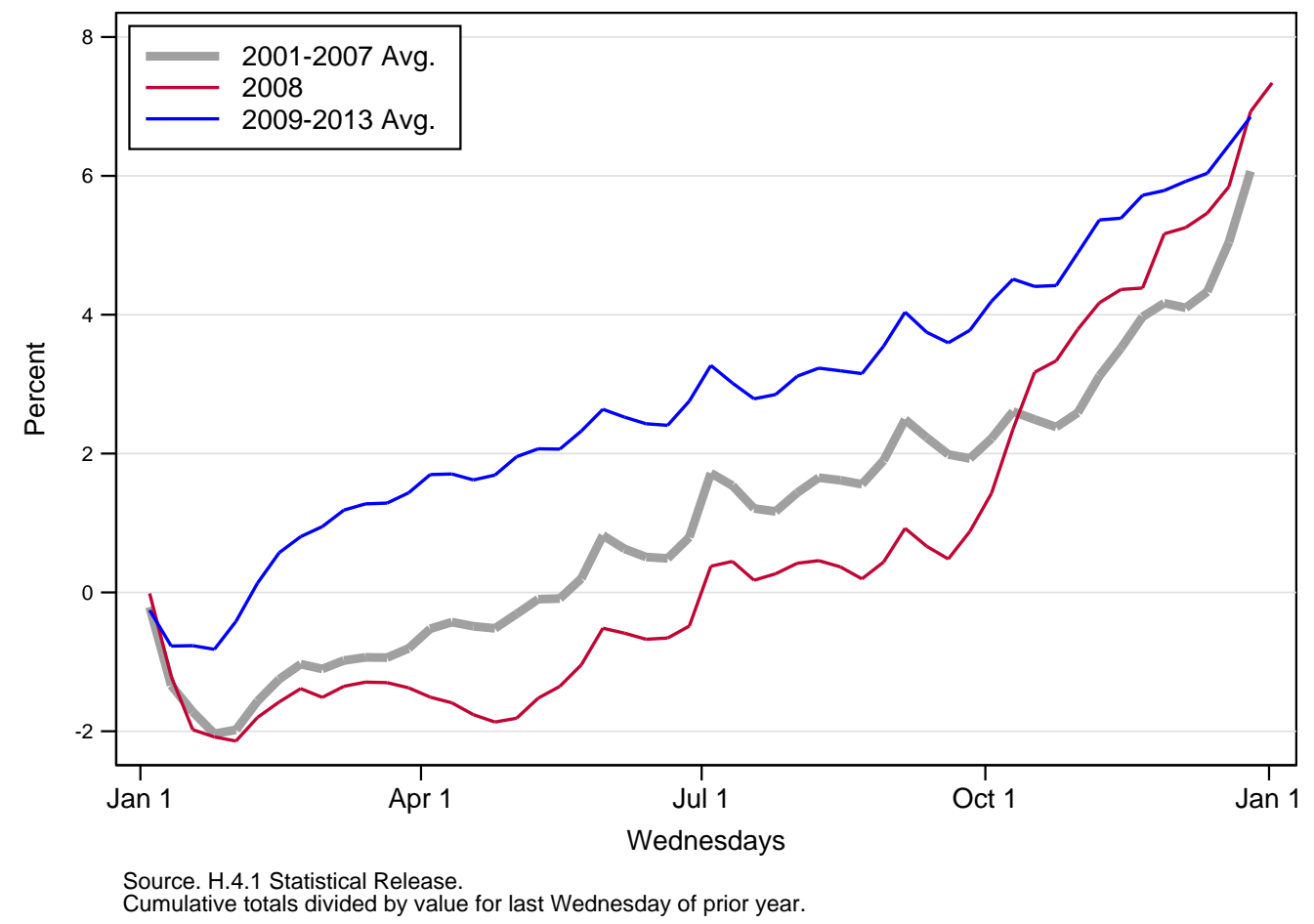

Figure A1: Cumulative change in currency in circulation

Table A1 shows the implication of a reduction in the annual currency growth from the assumed rate of 7 percent to the 4 percent average for the pre-crisis period. Differences between the two growth trajectories equate to differences in projected reserve balances at future year-end dates. Thus, 4 percent growth through 2020 reduces projected year-end Federal Reserve notes by $\$ 353$ billion relative to 7 percent growth, which implies $\$ 353$ billion 
more in reserve balances the Federal Reserve would have to be drained through SOMA sales or temporary operations to achieve a targeted level of reserves by the end of that year.

The three columns to the right show the estimated impact on Treasury remittances of currency growth at the 4 and 7 percent rates. Currency growth increases Treasury remittances by reducing reserve balances on which the Federal Reserve pays interest (interest on reserves, IOR), thereby reducing Federal Reserve Bank expenses and increasing earnings available to be paid to the Treasury. The current IOR rate is 25 basis points, which is at the top of the FOMC's target federal funds rate of $0-25$ basis points. To estimate the impact on future remittances, Blue Chip forecast federal funds rates were multiplied by the projected year-end currency levels.

Table A1: Federal Reserve note outcomes based on two currency growth paths

\begin{tabular}{cccccccc}
\hline \hline & \multicolumn{3}{c}{ Projected year-end } & Projected & \multicolumn{3}{c}{ Projected year-end } \\
Federal Reserve notes & fed. funds & \multicolumn{2}{c}{ Federal Reserve notes } \\
Year & $4 \%$ & $7 \%$ & Diff. & rate & $4 \%$ & $7 \%$ & Diff. \\
& $(1)$ & $(2)$ & $(2)-(1)$ & & $(3)$ & $(4)$ & $(4)-(3)$ \\
\hline 2014 & 1,232 & 1,269 & 37 & 0.30 & 4 & 4 & 0 \\
2015 & 1,284 & 1,361 & 77 & 1.00 & 13 & 14 & -1 \\
2016 & 1,338 & 1,460 & 122 & 2.25 & 30 & 33 & -3 \\
2017 & 1,394 & 1,566 & 172 & 3.50 & 49 & 55 & -6 \\
2018 & 1,452 & 1,679 & 226 & 3.75 & 54 & 63 & -8 \\
2019 & 1,513 & 1,800 & 287 & 4.00 & 61 & 72 & -11 \\
2020 & 1,576 & 1,929 & 353 & 4.00 & 63 & 77 & -14 \\
\hline \multicolumn{3}{c}{ Total for $2014-2020:$} & 273 & 317 & -44 \\
\hline
\end{tabular}

Note. We use Greenlaw, Hamilton, Hooper, and Mishkin (2013)'s assumptions. Billions of U.S. dollars, except as noted.

Currency growth at an average annual rate of 7 percent through 2020 would reduce cumulative IOR expenses from 2014 to 2020 by an estimated $\$ 317$ billion, while growth at an annual rate of 4 percent would reduce expenses by only $\$ 273$ billion. The difference between these amounts implies a $\$ 44$ billion cumulative reduction in Treasury remittances if currency grows at 4 percent rather than 7 percent. Annual differences in estimated remittances increase from less than $\$ 1$ billion in 2014 to $\$ 14$ billion in 2020 .

Based on their assumptions and interpretation of the FOMC's normalization strategy, Greenlaw, Hamilton, Hooper, and Mishkin (2013) expect annual remittances to the Treasury to peak at $\$ 105$ billion in 2014 . Thereafter, they expect remittances to decrease to a low of $\$ 33$ billion in 2018 and 2019 due to reductions to the SOMA and higher IOR expenses. Currency growth at a 4 percent annual rate would reduce these projected remittances to $\$ 25$ billion in 2018 and $\$ 22$ billion in 2019 and increase the probability that the Federal Reserve would suspend remittances to the Treasury during the later stages of normalization. 